ISSN 1999-4915

www.mdpi.com/journal/viruses

Review

\title{
Utility of the Bacteriophage RB69 Polymerase gp43 as a Surrogate Enzyme for Herpesvirus Orthologs
}

\section{Nicholas Bennett ${ }^{1}$ and Matthias Götte ${ }^{1,2,3, *}$}

1 Department of Microbiology and Immunology, McGill University, 3775 University Street, Montreal, Quebec H3A 2B4, Canada

2 Department of Biochemistry, McGill University, 3655 Sir William Osler Promenade, Montreal, Quebec H3G1Y6, Canada

3 Department of Medicine, Division of Experimental Medicine, McGill University, 1110 Pine Avenue West, Montreal, Quebec H3A 1A3, Canada

* Author to whom correspondence should be addressed; E-Mail: matthias.gotte@ mcgill.ca; Tel.: +1-514-398-1365; Fax: +1-514-398-7052.

Received: 1 December 2012; in revised form: 16 December 2012 / Accepted: 17 December 2012 / Published: 8 January 2013

\begin{abstract}
Viral polymerases are important targets in drug discovery and development efforts. Most antiviral compounds that are currently approved for treatment of infection with members of the herpesviridae family were shown to inhibit the viral DNA polymerase. However, biochemical studies that shed light on mechanisms of drug action and resistance are hampered primarily due to technical problems associated with enzyme expression and purification. In contrast, the orthologous bacteriophage RB69 polymerase gp43 has been crystallized in various forms and therefore serves as a model system that provides a better understanding of structure-function relationships of polymerases that belong the type $\mathrm{B}$ family. This review aims to discuss strengths, limitations, and opportunities of the phage surrogate with emphasis placed on its utility in the discovery and development of anti-herpetic drugs.
\end{abstract}

Keywords: DNA polymerase; T4 DNA polymerase; gp43; herpesviridae; UL30; UL54; HSV1; HCMV; RB69 DNA polymerase 


\section{Nomenclature}

HSV1 Herpes Simplex Virus 1

HSV2 Herpes Simplex Virus 2

VZV Varicella Zoster Virus

EBV Epstein-Barr Virus

HCMV Human cytomegalovirus

HHV6 Human Herpesvirus 6

HHV7 Human Herpesvirus 7

KSHV Kaposi's sarcoma-associated herpesvirus

PFA Phosphonoformic acid

PAA Phosphonoacetic acid

ACV Acyclovir

GCV Ganciclovir

CDV Cidofovir

\section{Introduction}

The eukaryotic viruses of the herpesviridae family are important human pathogens. In all, there are eight different human herpesviruses; Herpes simplex virus 1 and 2 (HSV1: HHV1 and HSV2: HHV2), varicella zoster virus (VZV: HHV3), Epstein-Barr virus (EBV: HHV4), Human cytomegalovirus (HCMV: HHV5), Human Herpes virus 6 and 7 (HHV6 and HHV7) and Kaposi's sarcoma-associated herpesvirus (KSHV, HHV8). Human herpesviruses cause a spectrum of diseases ranging from relatively benign cutaneous lesions to serious conditions like encephalitis and cancer. Viruses that belong to the herpesviridae family are characterized by their ability to establish lifelong, latent infections. Thus, a substantial proportion of the global population is seropositive for one or more herpesviridae viruses. Although individuals with a functioning immune system can generally keep the virus suppressed, the ability to form latent infections, and the fact that the virus is widespread in the human population means that herpesvirus reactivation is a major source of disease and morbidity in immunocompromised individuals.

The majority of approved antiviral drugs have been shown to inhibit the herpesvirus-specific DNA polymerase, reducing viral DNA replication, and, in turn, viral load [1]. However, although herpesvirus polymerases are all structurally related, they are not highly homologues. As a consequence, most drugs do not show broad antiviral activities against the various members of the herpesviridae. The nucleoside analog acyclovir (ACV) and its pro-drug valacyclovir are utilized to treat infection with HSV1, HSV2 or VZV, while the nucleotide analog ganciclovir (GCV) (or valganciclovir) and cidofovir (CDV) are approved to manage HCMV infection. The pyrophosphate analog phosphonoformic acid (PFA, foscarnet) provides an option to treat HSV1, HSV2, VZV and HCMV, if first-line drugs have failed to lower the viral burden. Like all current antiviral treatments, long-term treatment can lead to the development of drug resistance. Severe side effects and complicated treatment schedules represent other problems in the management of herpesvirus infection. 
Unfortunately, the development of assays to screen for novel anti-herpetic DNA polymerase inhibitors has been limited by technical problems. For the purpose of biochemical screens, herpesviridae DNA polymerases are difficult to overexpress in heterologous expression systems and have limited solubility. Hence, it has been difficult to characterize structural and functional details of these polymerases [2-8]. Of the eight human herpesvirus DNA polymerases, the best-studied is perhaps UL30 from HSV1. This enzyme has been characterized extensively biochemically and has been successfully crystallized [9]. Progress has also been made in characterizing HCMV UL54 [10,11]

In contrast to herpesviridae DNA polymerases, the orthologues enzymes of bacteriophage T4 (T4gp43) and "T4 like" bacteriophage RB69 (RB69gp43) are well studied. T4gp43 has been studied extensively using genetic, molecular biology, and biochemistry. Research into T4gp43 has been key to our current understanding of the dynamics of DNA replication [12]. RB69gp43 has been crystallized in various forms and therefore provides an important structural model for polymerases that belong to the same family [13-16]. It is here attempted to discuss the general aspects of structure and function of these related enzymes and the utility of RB69gp43 as a surrogate system for herpesviridae DNA polymerases in efforts to provide a better understanding of mechanisms of drug action and resistance.

\section{Structure and Function of B Family Polymerases}

DNA dependant DNA polymerases can be subdivided into five different families based on sequence and structural homology [17]. The DNA polymerases of bacteriophage RB69 and the herpesviridae are classified as B family polymerases (Figure 1a,b) [18]. B family polymerases have been identified in all domains of life and are primary involved in genome replication [19]. Unlike other polymerase families, the B family polymerases form part of a multi-subunit complexes, sometime referred to as the DNA replisome, which can co-ordinate both leading and lagging strand replication [17]. However, the polymerase catalytic activity of B family DNA polymerases is encoded by a single gene, which is sometimes referred to as the DNA polymerase catalytic subunit [20]. The catalytic subunit also often encodes an intrinsic 3'-5' exonuclease activity which provides proofreading. This substantially increases the accuracy of DNA synthesis [21,22]. The B family catalytic subunit, in the presence of the polymerase accessory proteins, is both high faithful in replicating DNA and are highly processive [12].

RB69 and each of the members of the herpesviridae family encode a B family polymerase (Figures 1 and 2). The virally encoded polymerase serves to replicate the viral genome. Both RB69gp43 [13] and HSV1 UL30 [9] have been studied using X-ray crystallography. Both polymerases are composed of five conserved structural domains, referred to as N-terminal, 3'-5' exonuclease, palm, fingers and thumb subdomains. In addition to these five conserved domains, the x-ray crystal structure of HSV1 UL30 showed an extra domain at the N-terminal end of the protein, which is called the pre N-terminal domain (Figure 1b).

Structures of RB69gp43 in various forms in the absence and presence of substrates provided a detailed insight into distinct events involved in nucleotide incorporation, as well as the dynamics of exonuclease function. The structure of the HSV1 UL30 apo enzyme shows a similar domain structure as seen with RB69gp43; however, the exact structural requirements for DNA and nucleotide binding have yet to be established in this case. HSV1 UL30 contains the particular conserved motifs shared by all B family polymerases (Appendix Figure A1). 
Figure 1. (a) Domain structure of HSV1 UL30 (pdb 2GV9) [9]. The pre N-terminal domain is shown in white, the N-terminal domain is yellow, the exonuclease domain is red, the palm domain is magenta, the fingers domain is blue and the thumb domain is green. (b) The structure of the RB69gp43 apo form (pdb file 1IH7) [15]. Both structures show the fingers subdomain the open conformation. Images were generated using Pymol [23].

(a)

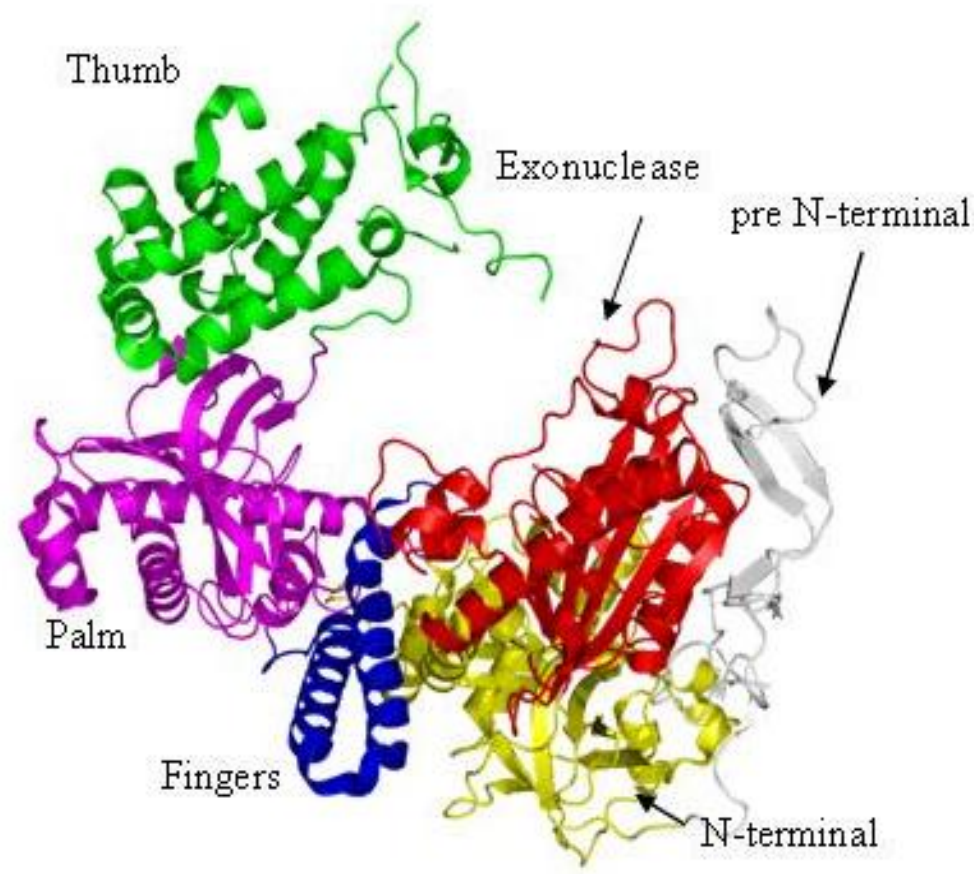

HSV1:UL30

(b)

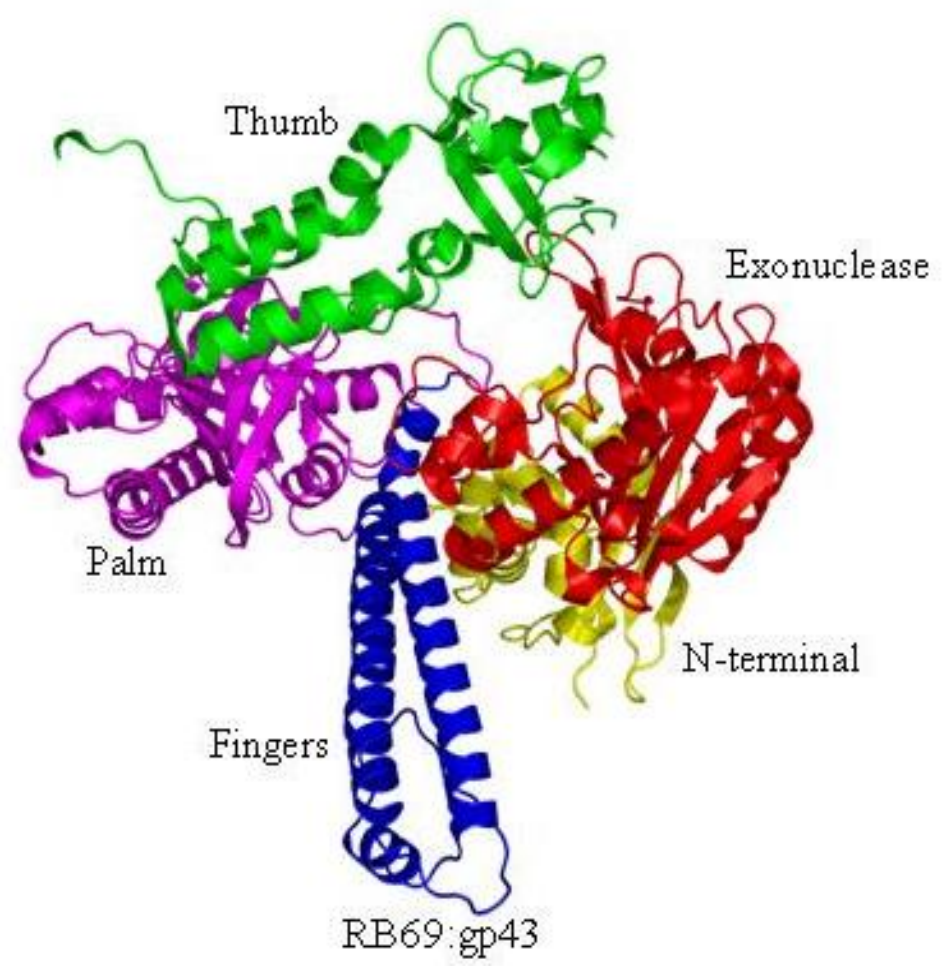


Figure 2. Protein sequence alignment of herpesvirus and bacteriophage polymerase finger domains. Herpesvirus and bacteriophage polymerase were aligned individually using the Muscle algorithm within Geneious [24,25]. The bacteriophage and herpesvirus sequences were then structurally aligned by RAPIDO [26]. Blocks above sequence highlight structural domains of polymerase. The palm domain is in pink. The fingers domain is in blue. The known conserved regions are shown in magenta blocks above sequence [27-31]. Secondary structural elements of HSV1 UL30 are indicated and are number according to Liu et al. (2006). Secondary structural elements of RB69 gp43 are indicated and are numbered according to Wang et al. (1997). Structural motifs are highlighted in sequence. $\mathrm{N}$ helix residues are in yellow. Motif $\mathrm{B}$ is in green. Mutations that have been associated with resistance to current anti-herpetic drugs are shown below the corresponding residue [32,33]. Resistance mutations are colored using the following scheme: Red: Pyrophosphate $^{R}$ (Resistant), Blue: Nucleotide ${ }^{R}$, Green: Pyrophosphate ${ }^{R}$ and Nucleotide ${ }^{R}$. Purple: Pyrophosphate ${ }^{\mathrm{HS}}$ (Hypersensitive), Brown: Nucleotide ${ }^{\mathrm{R}}$ but Pyrophosphate ${ }^{\mathrm{HS}}$.

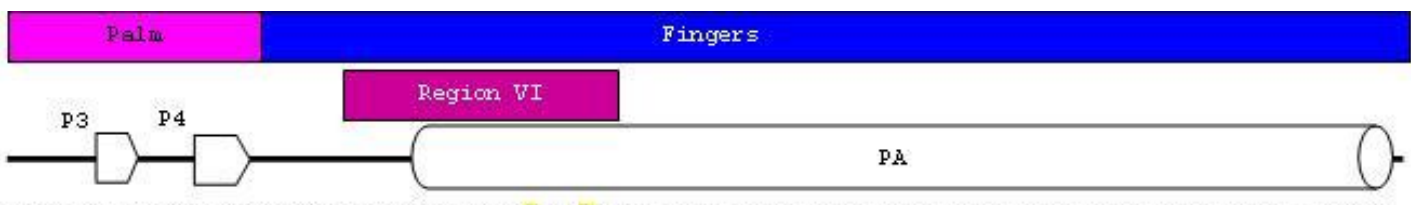

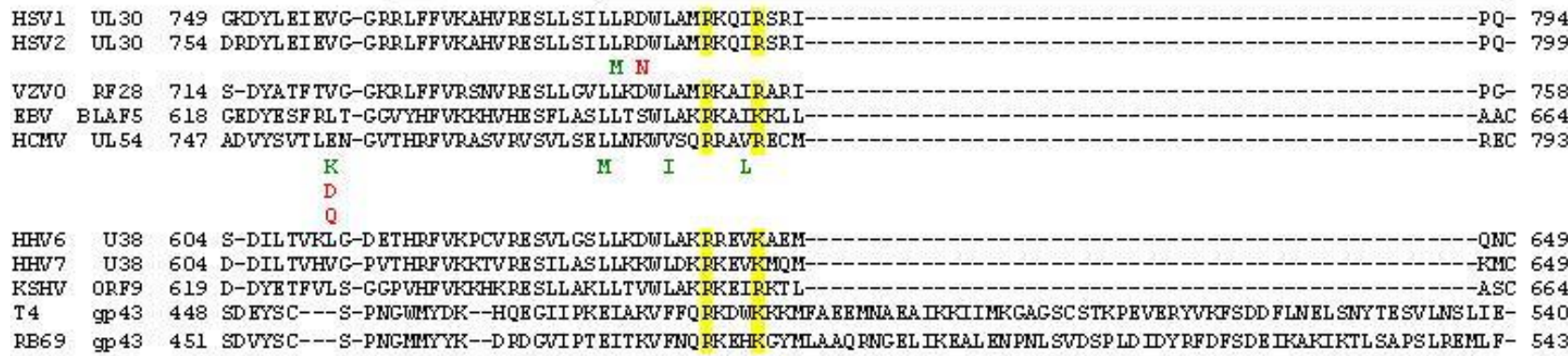

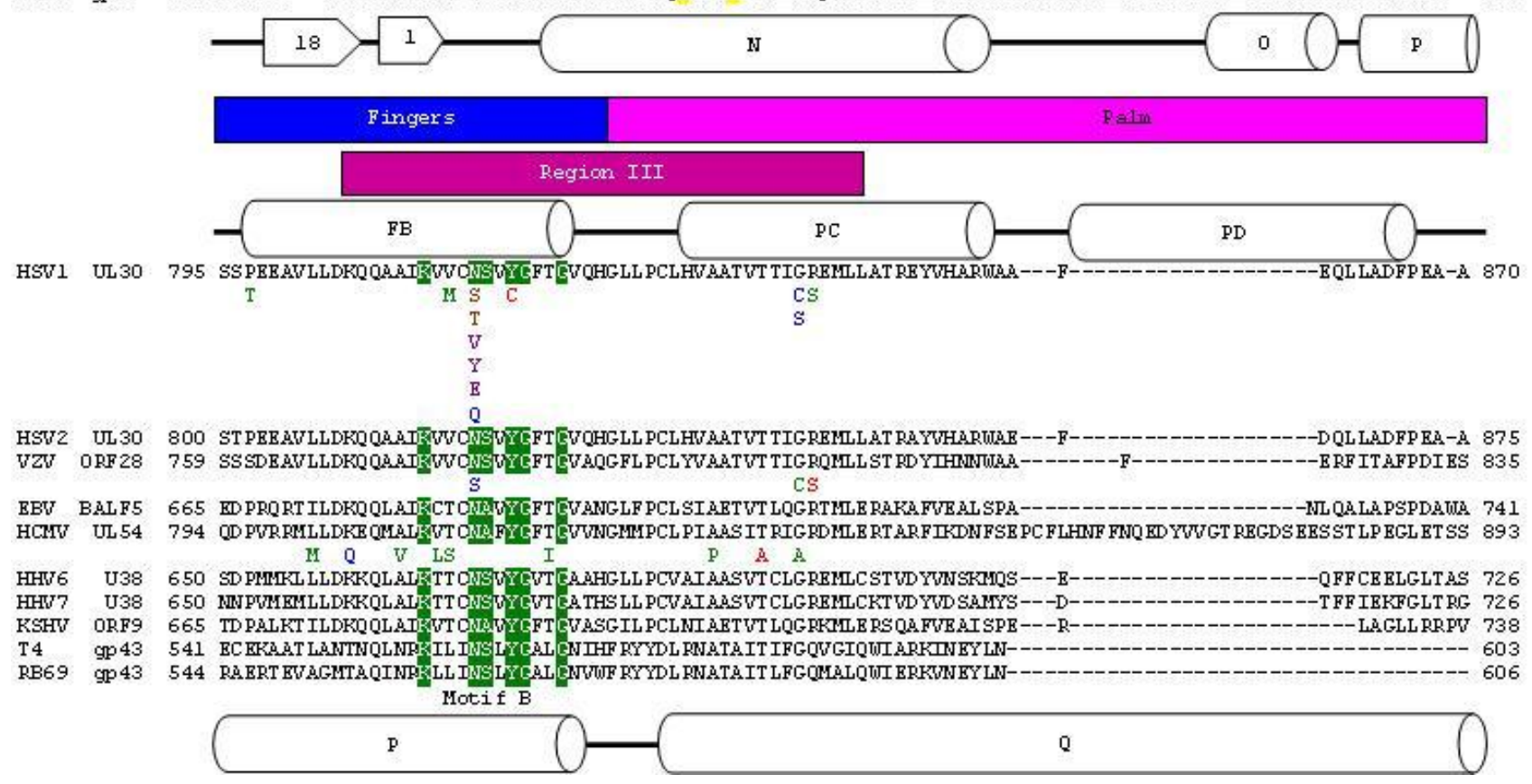




\section{Subdomains of B Family Polymerase}

Protein sequence alignments of HSV1 UL30 to other herpesviridae DNA polymerase show that it is likely that all Human herpesviridae DNA polymerases contain a pre-N terminal domain [9]. The exact function of the pre-N terminal this domain remains elusive. The pre- $\mathrm{N}$ terminal domain also contains the FYNPYL motif specific to herpesviridae family polymerases (Appendix Figure A1) [9]. It has recently been shown that this motif is required for efficient replication of viral DNA synthesis in vivo; a mutant polymerase lacking the FYNPYL motif showed a substantial reduction in viral DNA synthesis [34]. However, the purified FYNPYL deletion mutant showed no reduction in polymerase activity, suggesting that this motif may have a function in the formation of the viral DNA replisome.

The N-terminal domain shows a $\beta \alpha \beta \beta \alpha \beta$ fold, which has been found in some RNA binding proteins [9,35]. In addition, the crystal structure of the RB69 gp43 contains a rGMP bound to the $\mathrm{N}$-terminal domain [15], and some mutations in the N-terminal domain of T4gp43 decrease the expression of the polymerase leading to the suggestion that the $\mathrm{N}$-terminal domain may be involved in expression regulation [36]. However, in spite of these observations, the functional role of this domain remains to be defined.

The sequence of the 3'-5' exonuclease domain of B family polymerases is not highly conserved. However, all 3'-5' exonuclease domains currently characterized adopt a ribonuclease H-like (RNase $\mathrm{H}$-like) fold. The RNase $\mathrm{H}$ fold brings four highly conserved negatively charged residues together to form the active site. In both RB69gp43 and HSV1 UL30 these residues have been identified as three aspartic acids and a glutamic acid. These residues are essential for the binding of two divalent, catalytic metal ions. Structural elements, that harbor active site residues in RB69gp43, are referred to as exoI (D114, E116), exoII (D222), and exoIII (D327) (Table 1, Appendix Figure A1). In herpesviridae polymerases the equivalent regions are referred to as ExoI, region IV and Delta $(\delta) \mathrm{C}$, respectively. In HSV1 UL30 these residues are; ExoI, D368 and E370, region IV or ExoII, D471 and delta C or ExoIII, D581 (Table 1, Appendix Figure A1).

The polymerase active site of B family polymerases is made up of the three domains; the palm, fingers and thumb domains. Together they adopt the classic right hand conformation seen in all available structures of viral polymerases (Figure 1). Two highly conserved motifs in the palm domain, one in the fragment of the palm domain prior to the fingers domain called motif $\mathrm{A}$ and one in the fragment post fingers domain called motif $\mathrm{C}$ (Table 1, Appendix Figure A1) are likewise seen as signature motifs. In herpesviridae polymerases these domains are referred to as region II and region I, respectively. These motifs are; motif A; DXXLYPS and motif C; DTDS (Table 1, Appendix Figure A1). Structurally, these motifs fold together to form a three-strand anti-parallel $\beta$ sheet (Figure 3c) [13]. Two conserved aspartic acid residues, D411 from motif A and the D625 from motif $\mathrm{C}$, are required to form critical interactions which help co-ordinate the two divalent metal cation that are critical for DNA polymerization (Figure 3b) [15]. In addition, to motif A and C there are two other conserved motifs which also form parts the active site, motif B (KXXXNSXYG), which is known as Region III in herpesviridae, which is located on the helix $\mathrm{P}$ of the fingers domain, and the KKRY motif which is in the palm domain sequentially after motif $C$ (Appendix Figure A1). 
Table 1. Comparison of size, weight and position of conserved motifs or active site residues of RB69 and herpesviridae DNA polymerases. The position conserved motifs where assigned based on alignments generated using geneious [24].

\begin{tabular}{|c|c|c|c|c|c|c|c|c|c|c|}
\hline Virus (Gene) & $\begin{array}{l}\text { Amino Acids } \\
\text { (aa) }\end{array}$ & $\begin{array}{c}\text { Weight } \\
\text { (kDa) }\end{array}$ & $\begin{array}{c}\text { FYNPYL } \\
\text { motif }\end{array}$ & Exo 1 & $\begin{array}{c}\text { Exo2/region } \\
\text { IV }\end{array}$ & $\begin{array}{l}\text { Exo3/delta } \\
\text { (ä) } \mathrm{C}\end{array}$ & $\begin{array}{c}\text { Motif } \\
\text { A/region II }\end{array}$ & $\begin{array}{c}\text { Motif } \\
\text { B/region III }\end{array}$ & $\begin{array}{c}\text { Motif } \\
\text { C/region I }\end{array}$ & KKRY moti \\
\hline RB69 (gp43) & 903 & 104.47 & N/A & $113-117$ & 222 & 327 & $411-420$ & $560-571$ & $621-624$ & $804-807$ \\
\hline HSV1 (UL30) & 1236 & 136.42 & $167-173$ & $367-371$ & 471 & 581 & $717-726$ & $811-822$ & $886-889$ & 938-941 \\
\hline HSV2 (UL30) & 1241 & 137.32 & $166-172$ & $368-372$ & 472 & 582 & $722-731$ & $816-827$ & 891-894 & 943-946 \\
\hline VZV (Orf28) & 1195 & 134.05 & $7-13$ & $348-352$ & 452 & 562 & $682-691$ & 775-786 & $851-854$ & 903-906 \\
\hline EBV (BALF5) & 1016 & 113.43 & $6-12$ & $295-299$ & 384 & 497 & $584-593$ & 681-692 & $755-758$ & $807-810$ \\
\hline HCMV (UL54) & 1242 & 137.21 & $2-8$ & $300-304$ & 413 & 542 & $717-726$ & $811-822$ & 910-913 & $962-965$ \\
\hline HHV6 (UL38) & 1013 & 115.67 & $6-12$ & $281-285$ & 369 & 482 & $572-581$ & $666-677$ & $740-743$ & $792-795$ \\
\hline HHV7 (UL38) & 1014 & 115.91 & $6-12$ & $280-284$ & 368 & 480 & $572-581$ & $666-677$ & 740-743 & 792-795 \\
\hline KSHV (Orf9) & 1013 & 113.33 & $3-9$ & 295-299 & 383 & 498 & $585-594$ & $681-692$ & $752-755$ & 804-807 \\
\hline
\end{tabular}


Figure 3. (a) Superpositioning of open and closed structures of RB69 gp43 showing finger domain movement. This diagram is composed of RB69 gp43 in the fingers closed position (pdb 3LDS) [37] and in the fingers opened position (pdb 1IH7) [15]. (b) Polymerase active site of RB69 gp43 showing interactions between conserved residues of motif A and C, metal ions A and B and dNTP and interactions between K560 and dNTP. This image is an aligned composite image of pdb 3LDS [37] and 3SCX [38]. (c) Structural alignment of the polymerase active site of RB69gp43 (pdb 3LDS) and HSV1 UL30 (pdb 2GV9). RB69 gp43 backbone is in light blue while the HSV1 UL30 backbone is in light orange. Active site residues of RB69 gp43 are indicated. RB69 gp43 motif A is in magenta, motif C is in orange and KKRY is in purple. HSV1 UL30 motif $\mathrm{A}$ is in pink, motif $\mathrm{C}$ is in light orange and KKRY is in light purple. Images were generated using Pymol [23]. (d) Generalized diagram of the polymerase catalytic cycle showing steps at which inhibitors can act. Nucleotide inhibitors, once incorporated, prevent further extension of the DNA primer, by inhibiting nucleotidyl transfer. Whereas, pyrophosphate inhibitors mimicking the pyrophosphate leaving group, stabilizing the pre-translocation complex and prevent translocation.

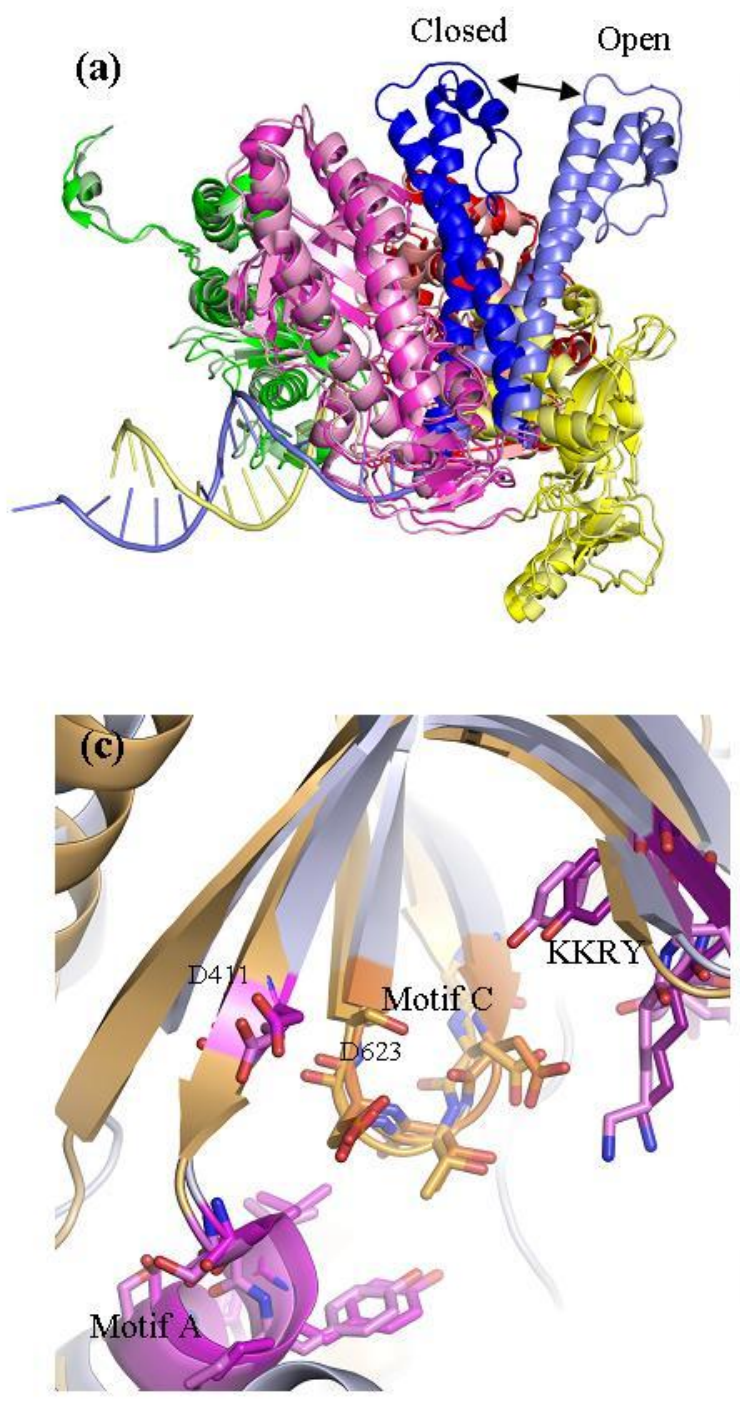

(b)

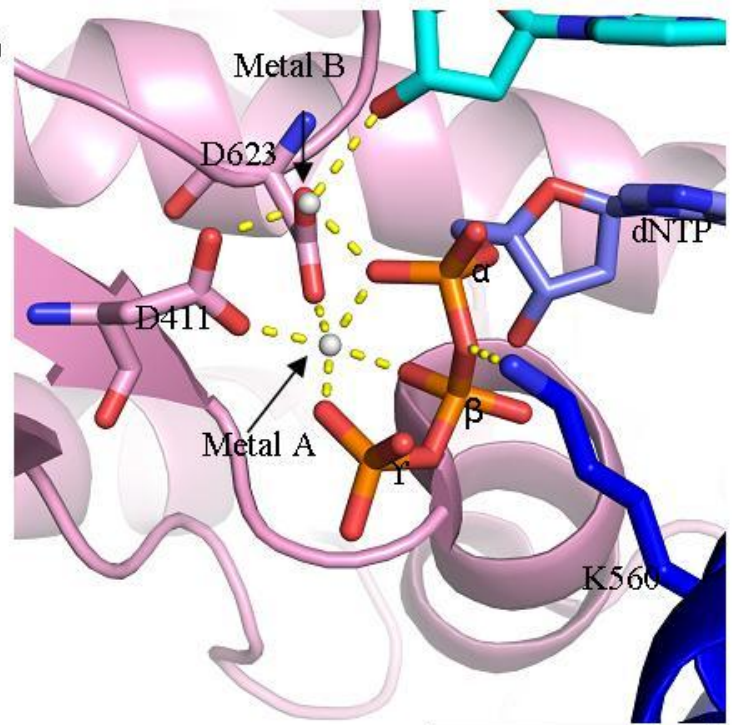

(d)

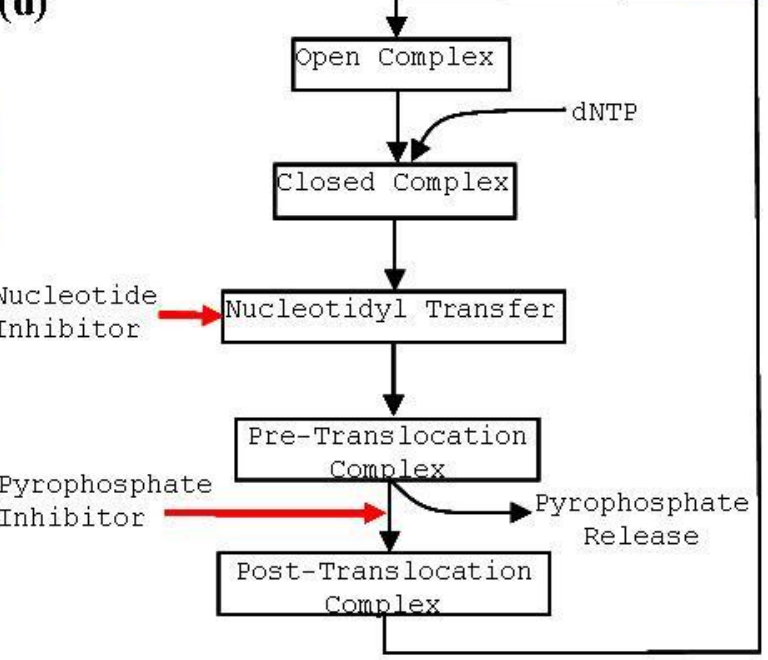


Residues K560 and N564 of motif B are important in coordinating the tri-phosphate tail of the incoming dNTP during catalysis [15]. Lysine 560 also serves as a proton donor during catalysis (Figure 3b) [39]. Residue Y567 of motif B has been shown to be involved in forming an important interaction with the minor groove of the DNA [40]. This interaction has been shown to be highly important in maintaining polymerase fidelity [40]. In addition to motif $\mathrm{B}$ of helix $\mathrm{P}$, there are also conserved positively charged residues within helix $\mathrm{N}$ (R482 and K486) that form important interactions with the tri-phosphate tail of the incoming dNTP during catalysis.

The KKRY motif is primarily involved in stabilizing the B form of DNA. Residue Y708 forms a hydrogen bond with the 3 ' terminus of the primer while the K705 and R707 form interactions with the phosphate backbone. Together, these interactions help stabilize the interactions between base pairs of the primer and template strands [15].

\section{Catalytic Cycle of B Type Polymerase RB69gp43}

Both RB69gp43 and HSV1 UL30 have been crystallized in the so-called open conformation [9,13], but only RB69 has been crystallized in the closed conformation [15]. The closed conformation of a ternary complex contains a DNA primer-template pair and a trapped nucleotide. The most striking difference between the open and closed formation of RB69gp43 is the movement of the fingers domain. Structural alignment of the open and close conformation of RB69gp43 shows that, upon dNTP binding, the fingers domain rotates $60^{\circ}$ inwards relative to the palm domain, with the tip of the fingers moving approximately $30 \AA$ (Figure 3a) [15]. Closure of the fingers domain moves the residues on helix $\mathrm{N}$ and $\mathrm{P}$ that are involved in binding the tri-phosphate tail of the incoming $\mathrm{dNTP}, 4-8 \AA$ closer to the polymerase active site. This action traps the dNTP in the active site and allows the nucleotidyl transfer to take place. By contrast, the overall structure of the thumb and palm domain between the open and closed conformation remains relatively unchanged. The thumb domain moves approximately $8^{\circ}$ toward the palm domain. This action wraps the minor groove of primer-template duplex [15].

B family polymerases employ a two divalent metal ion mechanism for the nucleotidyl transfer [41], in conjunction with a concurrent two proton transfer reaction $[39,42]$. The catalytic ions are bound by D411 of motif A and D623 of motif C, and form an extensive network of interactions with the dNTP aligning it in the correct orientation for polymerization (Figure 3b). Metal ion A is required to activate the 3 '-OH of the primer terminus. Interaction between metal ion A and the primer terminus attract the primer terminus closer to the $\alpha$-phosphorus atom of the incoming dNTP. This lowers the pKa of the 3'-OH group allowing it to be deprotonated, which facilitates the nucleophilic attack on the $\alpha$-phosphorous atom of the nucleotide substrate [43]. Metal ion B orientates the dNTP triphosphate tail and helps stabilizes the transition states; it has also been suggested that it assists in pyrophosphate release [38]. In RB69gp43, lysine 560 acts as a proton donor [42] and is required to protonates the pyrophosphate leaving group, which may facilitate its release from the complex. This step formally ends the catalysis, leaving the complex now in the pre-translocational state. The fingers of the polymerase rotate away from the active site allowing the release of the pyrophosphate, which allows the DNA substrate to translocate relative to the enzyme. This movement shifts the new 3'-OH terminus 
into the 1+ position forming a post-tranlocated complex with the polymerase reset for a new catalytic cycle. Polymerases are in general able to discriminate between correct and incorrect nucleotides [44]. Incorrect binding of a nucleotide destabilizes the closed ternary complex, which enables the fingers domain to return to the open form releasing the incorrect nucleotide. Effective discrimination against the incorrect nucleotide at the level of substrate binding raises the fidelity of DNA synthesis significantly[45]. However, in B family polymerases, if an incorrect nucleotide is indeed incorporated, these enzymes can switch into the 3'-5' exonuclease mode and remove the misincorporated base. The 3'-5' exonuclease activity has been shown to increases the fidelity of the RB69 polymerase from the Exo $^{-}$rate of 2.8 errors per genome $\left(\mu_{\mathrm{g}}\right)$ to the Exo ${ }^{+}$error rate of $4 \times 10^{-3} \mu_{\mathrm{g}}$ [40,46]. The excision of an incorrectly incorporated terminal nucleotide is also dependant on two divalent metal ions. Structures of RB69gp43 have shown that the exonuclease active site is located approximately $40 \AA$ from the polymerase active site [47]. Thus, for 3'-5' exonuclease activity to occur the DNA primer-template terminus must be translocated from the polymerase active site to the exonuclease site. The details of this process remain to be defined. It has been suggested that DNA replication accessory proteins, particularly the sliding clamp gp45, may be involved in the process of translocating DNA from polymerase to exonuclease active site [15]. It has also been shown that a $\beta$ hairpin loop between residues 251-262 is important for exonuclease function [48,49]. This loop is involved in stabilizing the frayed base pair at the exonuclease active site allowing the removal of the incorrect nucleotide. During translocation from the polymerisation active site to the exonuclease active site the primer-template pair is partially melted, producing three unpaired bases. The three unpaired bases of the primer strand are then sequestered into the exonuclease active site, which facilitates the excision. Structures of RB69gp43 poised with its primer-template in the exonuclease mode are available $[47,48]$.

\section{Base Selectivity in RB69 DNA Polymerase}

A large number of mutant RB69 and T4 DNA polymerases that affect both efficiency and fidelity of DNA replication have been isolated and characterized. In the case of RB69, X-ray crystallography has firmly established the nucleotide binding site at the atomic level. Crucial residues include K560 (Motif B), L415 and Y416 (Motif A) and L561 (Not conserved), Y567 and G568 (Motif B) [50].

Conserved residue Motif A has been shown to be important for sugar selectivity. Y416 forms a stacking interaction with deoxyribosyl moiety of the incoming dNTP [15]. It has been proposed that the 2'-OH group of a mismatched rNTP would cause a steric conflict with Y416 preventing formation of a stable complex [51]. Biochemical experiments with the Y416A mutant enzyme corroborated this notion. Unlike the wild type, the mutant was able to incorporate $\mathrm{rCTP}$, ddCTP, and dCTP at similar rates [51].

Residue Y567 of motif B has been shown to be important in maintaining the fidelity of base selection [40,52]. This residue forms an interaction — via a water molecule — with the minor groove of the terminal primer-template pair. This interaction is important for sensing the geometry of the newly form base pair and thus detecting distortions caused by incorrect base pairing [15]. Mutations to residue 567 increase the size of the nascent base-pair-binding pocket allowing the misincorporation of nucleotides. 
Residue L561 protrudes into the major groove of the templating base. It has been proposed that this residue is involved in detecting mismatches that lead to distortion of the major groove. L561A mutant confers a mutator phenotype [53]. Interestingly, the equivalent residue in herpesvirus-associated polymerases are not conserved (Figure $4 b$ ).

Figure 4. (a) Diagram of RB69 Fingers domain showing location of ABC block mutation relative to $\mathrm{dNTP}$ binding residues. Motif $\mathrm{B}$ residues are in orange, Tri-phosphate interacting residues on Helix $\mathrm{N}$ are in yellow, Block $\mathrm{A}$ is in red, Block B is in dark blue and Block $\mathrm{C}$ is in yellow. Aligned image of pdb 3LDS (dNTP) and pdb 3KD5 (N and P helix). (b) Sequence alignment of RB69 and herpesviridae sequences showing location of block mutations. (c) Diagram showing clash between W478 of Block A and W365. RB69 ABC5 is in white (3KD5), RB69 WT is in blue (pdb 1IH7) and HSV1 UL30 is in orange (pdb 2GV9). (d) Diagram of RB69 ABC5 block mutations active site showing phosphonoformic acid binding in $\beta$ and $\gamma$ phosphate position and with acyclovir in the pretranslocation position (pdb 3KD5). Images were generated using Pymol [23]. Alignment was generated using Geneious [24].

(a)

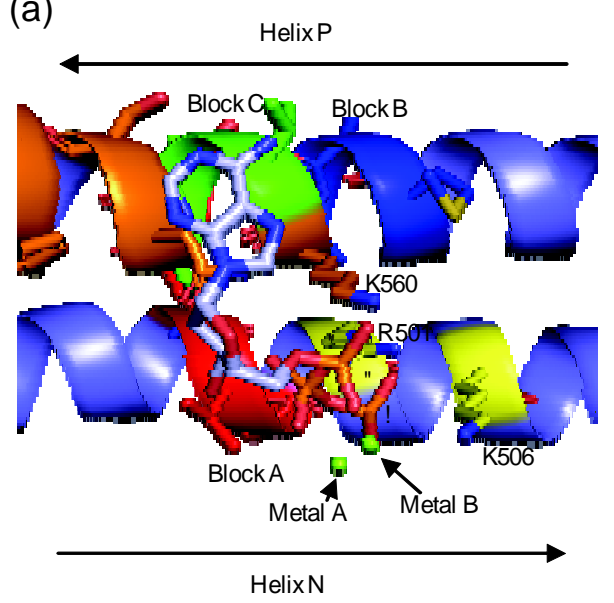

(c)

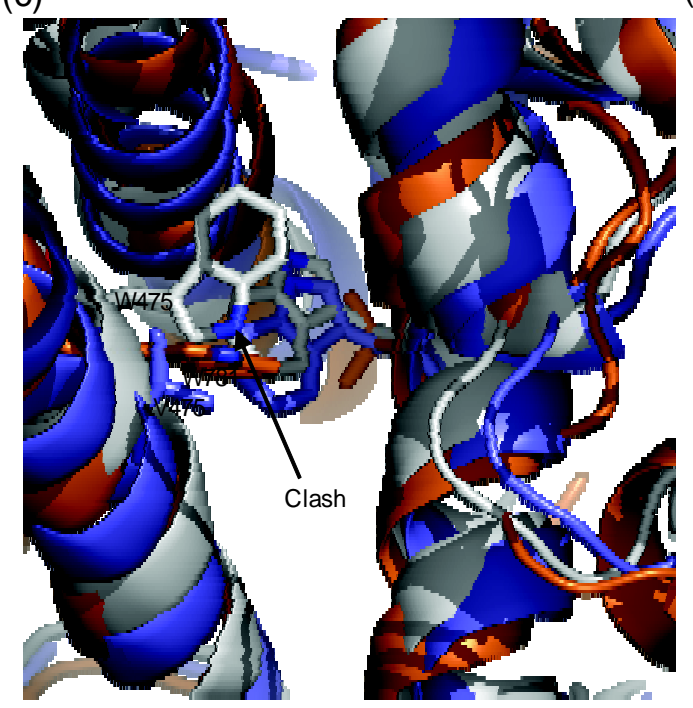

(b)
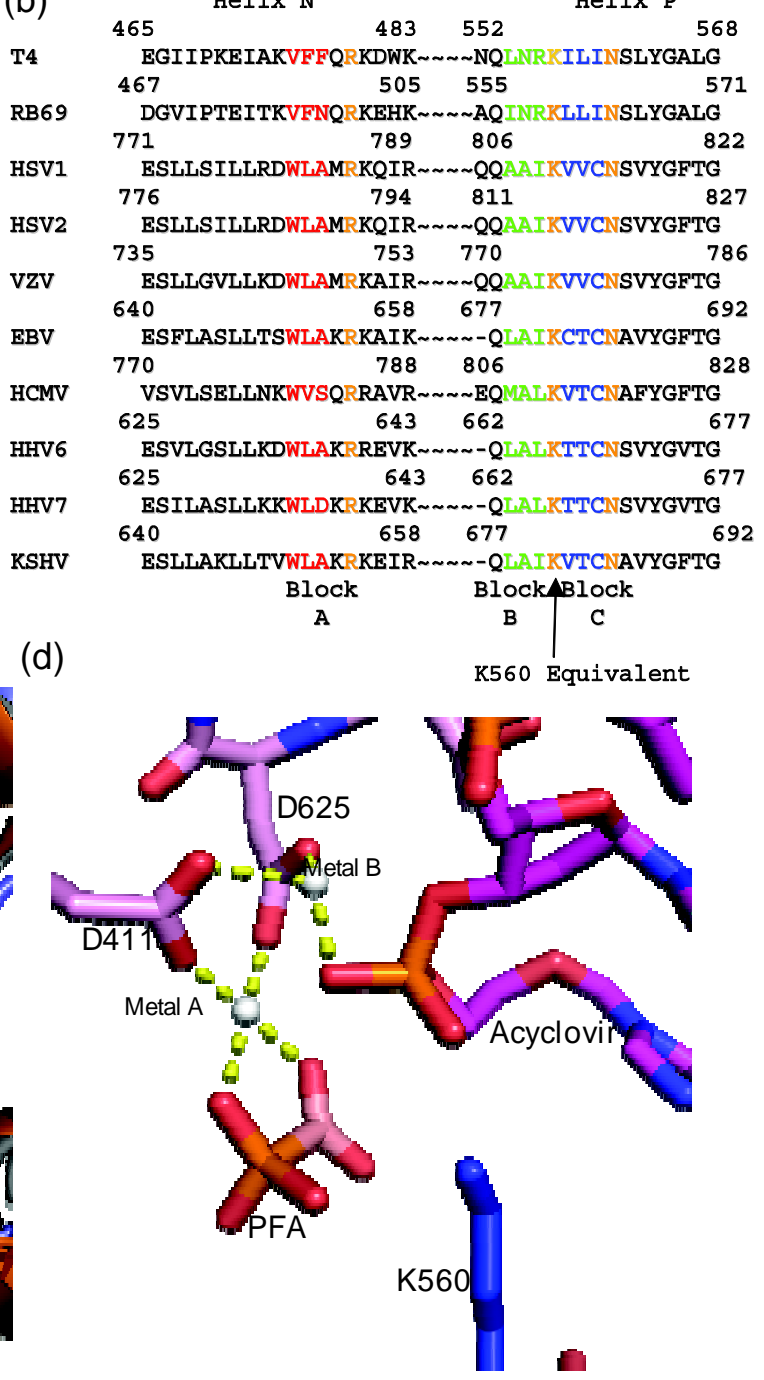


\section{The Active Site of HSV1 UL30 and RB69gp43}

At both the nucleotide and amino acid level, herpesviridae polymerases are not highly conserved (Appendix Figure A1). They range in length from 1013-1236 aa, and range in molecular weight from 113 to $137 \mathrm{kDa}$ (Table 1). RB69gp43 is relatively small with 903 aa in length and a molecular weight of $104 \mathrm{kDa}$ (Table 1). In terms of homology, there is very low homology between RB69gp43 and herpesviridae DNA polymerases sequences. However, both RB69gp43 and herpesviridae contain all the conserved motifs associated with B family polymerases (Appendix Figure A1).

Unlike herpesvirus DNA polymerases, there is a wealth of information on the structure and function of RB69gp43. Thus, this enzyme is often used as a model for herpesviridae DNA polymerase. Because of the shared conserved motifs between $\mathrm{B}$ family polymerase it is reasonable to assume that both herpesviridae and RB69gp43 have a similar, if not an identical catalytic mechanisms. The residues of motif $\mathrm{A}$ and $\mathrm{C}$ in the HSV1 UL30 and RB69gp43 structure are superimposable, supporting the notion that the function of these residues is similar (Figure 3c). In contrast to the metal cation-binding portion of the active site, the residues of helix $\mathrm{N}$ and $\mathrm{P}$ of the fingers domain vary greatly between HSV1 UL30 and RB69 gp43. On helix N, the only conserved residues are two basic amino acids R482 and K486 in RB69 gp43, and R785 and R789 in HSV1 UL30. Likewise, on the helix P, the only conserved residues are those of motif B: K560 to N565 in RB69gp43 and K811 to N815 in HSV1 UL30. Thus, the non-conserved residues of helix $\mathrm{N}$ and $\mathrm{P}$ account for the major differences in the nucleotide binding site, which could in turn account for the difference in sensitivity to antiviral drugs when herpesviridae polymerases are compared with RB69gp43. This notion is supported by biochemical studies with mutant enzymes derived from HCMV UL54 (see below) [11].

\section{Mutations of Bacteriophage T4 that Induce PAA Sensitivity}

There are several known natural mutations of bacteriophage T4 DNA polymerase (T4gp43) that affect sensitivity to the pyrophosphate analog phosophonoacetic acid (PAA). T4gp43 is highly homologues to RB69gp43, and, like RB69gp43, is naturally resistant to PAA. However, mutants of bacteriophage T4 with reduced plaque formation in the presence of PAA have been identified [54,55]. One of these mutations, L412M, is located in the conserved motif A. L412M confers increased sensitivity to PAA and interestingly also confers mutator properties to the polymerase [54]. Another interesting feature of the L412M mutant phage is that it can replicate in E. coli strains with restricted dGTP pools (optA1). The ability to grow under these conditions suggests that the mutant polymerase can make more efficient use of the nucleotide substrates. Because fidelity of DNA synthesis is in part controlled by the rate with which a frayed primer switches from polymerase to exonuclease activity, a bias toward stabilizing the frayed primer in the polymerase active site would cause an overall reduction in enzyme fidelity. When this hypothesis was tested with purified T4gp43 L412M enzyme, it was found that T4gp43 L412M exhibited less exonulease activity in relation to the wild type supporting the notion that the L412M mutation was in fact changing the partitioning between exonuclease and polymerase activity away from exonuclease activity. The equivalent residue to L412 in RB69gp43 is L415. Mutations at this residue show increased rates of mis-incorporation [56]. Interestingly, several suppressor mutants of L412M were also isolated. When subjected to a similar analysis, they were 
found to be antimutator mutations and unable to grow on E. coli optA1 [55]. Mutations R335C and $\mathrm{S} 345 \mathrm{~F}$ are both located within the delta $\mathrm{C}$ region of the exonuclease domain (Appendix Figure A1). It has been proposed, that these mutation may affect pyrophosphate sensitivity by increasing the opportunity for exonuclease activity [54]. Since the primer terminus needs to be physically transferred to the exonuclease site, any increase in stability of the primer-terminus in the exonuclease active site or decrease of stability of the primer-terminus in the polymerase active site would increase the disruption of the pyrophosphate analog inhibited complex and henceforth increase the polymerase resistance to inhibition by pyrophosphate analogs. Interestingly in the RB69gp43 crystal structure the equivalent residue to R335 is R338, which is positioned at the very $\mathrm{C}$ terminus of the exonuclease domain and points into the cleft in which the finger domain rotates into during catalysis. Thus, the R335 mutation may not directly affect exonuclease function, but may instead inhibit finger domain movement [57].

\section{Chimeric Enzymes}

Tchesnokov et al. (2009) engineered an RB69gp43-UL54 chimeric enzyme, by mutating the active site of RB69gp43 to include the non-conserved elements from helix $\mathrm{N}$ and P of the HCMV enzyme. Swapping the polymerase active sites produced an enzyme that can be expressed in E. coli, and is soluble and easily purified. Biochemical assays have shown that the chimeric enzyme is sensitive to the nucleotide inhibitor acyclovir and the pyrophosphate analog PFA [58].

Three blocks of non-conserved amino acid residues were considered to engineer the chimera. Block A is located on helix N, and consists of residues 478-480 from RB69gp43 (VFN), these residue were replaced with equivalent residues of HCMV UL54: residues 779 to 781 (WVS). Block B and Block C are both located on Helix P. Block B consist of residues 557-559 of RB69gp43 (INR) and Block C 561-563 (LLI) of RB69gp43 where replaced with residues 808-810 (MAL) and 812-814 (VTC) from HCMV UL54, respectively. Block B and C flank residue K560, which is the conserved basic amino acid that likely donates a proton to the pyrophosphate leaving group [39,42]. Previous studies had already shown that several amino acids within this region can affect sensitivity to PFA (Figure 2) [11]. The chimeric polymerase reproduces drug sensitive and drug resistant phenotypes in cell-free biochemical assays, which validates this enzyme as a model system for polymerase active site inhibitors.

The structure of the chimera provides a detailed understanding of the mechanism of action of PFA [59]. The enzyme was co-crystallized in complex with a primer-template terminated with acyclovir in the presence and absence of PFA. PFA is bound at the polymerase active site and traps the enzyme in the pre-translocational state. The compound interacts with metal ion B and residue R482 of helix $N$, similar to the interactions formed by the $\beta$ - and $\gamma$-phosphate of a bound dNTP in the post-translocational conformation. It appears that W478 of block A is critical in mediating sensitivity to PFA. Although no additional contacts are formed, this residue likely reduces the population of complexes that exist in the open conformation due to steric interference with W365 on helix J. Generally binary complex structures of B family polymerase are found to be in the open conformation; however, in the case of the chimeric enzyme the fingers are in the closed conformation even in the absence of PFA [59]. The predicted steric clash was confirmed with enzymes containing amino acid substitutions at residues 478 and 365 [59]. 


\section{Resistance to Antiviral Drugs}

Resistance-conferring mutations in the polymerase of HSV1, HSV2, VZV and HCMV UL54 have been identified in vivo and in vitro [10,32,33,60]. Drug resistance is measured as an increase in the inhibitory concentrations of a given drug required to block $50 \%$ viral replication $\left(\mathrm{IC}_{50}\right)$. In HSV1, HSV2 and VZV an $\mathrm{IC}_{50} \geq 4.4 \mu \mathrm{M}$ confers significant levels of resistance to acyclovir [32], and in $\mathrm{HCMV}$ an $\mathrm{IC}_{50} \geq 12 \mu \mathrm{M}$ confers significant levels of resistance to ganciclovir, and $\mathrm{IC}_{50} \geq 400 \mu \mathrm{M}$ to PFA [60]. Because of the difficulties of purifying Herpesvirus DNA polymerase the many resistance mutation have only been assessed in cell-based phenotypic assays [60].

All known resistance mutations can be roughly divided into two groups: 1 . mutations within the exonuclease domain, which may affect 3'-5' exonuclease function, and 2. mutations within the domains that make up the polymerase active site, which may therefore affect polymerase function directly (Appendix Figure A1). Within the 3'-5' exonuclease domain there are several resistance mutations around the active site residues exo 1, exo2 and exo 3 respectively (Appendix Figure A1). Many of these mutations have been characterized to impair $3^{\prime}-5^{\prime}$ exonuclease activity [61,62]. Interestingly some of these resistance mutations have been characterized to confer resistance to pyrophosphate inhibitors but hypersensitivity to nucleotide inhibitors. An example of this phenotype is the HSV1 mutations Y577H and D581A [62] (Appendix Figure A1). Both mutations are located within the delta $\mathrm{C}$ region close to the exo 3 residue. Both mutations have been shown to impair exonuclease activity [62]. Logically a polymerase impaired in $3^{\prime}-5^{\prime}$ exonuclease activity would be unable to remove an incorporated nucleotide inhibitor from viral DNA, which would increase the viruses sensitivity to nucleotide inhibitor, thus explaining the hypersensitivity phenotype. However, the mutations also affect pyrophosphate inhibitors potency and this effect is harder to reconcile. Since pyrophosphate inhibitors mimic the pyrophosphate leaving group, and thus are not incorporated into DNA, the presence or absence of exonuclease activity should not directly affect pyrophosphate analog inhibitors susceptibility. The analysis of T4gp43 PAA sensitive mutants provides some possible insight into a mechanism [54,55]. While working with the T4gp43 L412M mutant they identified several suppressors of PAA sensitivity [54]. These suppressor mutants were shown to be antimutator polymerases, implying that $\mathrm{L} 412 \mathrm{M}$ suppressor mutant polymerase were likely to have an altered rate of exonuclease activity compared to the L412M mutants. The authors suggested that because pyrophosphate analogs competitively inhibit polymerase activity by mimicking the pyrophosphate leaving group, that the transition to exonuclease activity could potentially bypass inhibition. Thus, altering the rate of exonuclease activity could potentially affect pyrophosphate inhibitor potency. Unfortunately this hypothesis has not fully been tested in either T4gp43 or herpesviridae DNA polymerases.

Resistance mutations within the polymerase active site can be arbitrarily split into two groups: 1. Fingers domain mutations and palm domain mutations. In HSV1, HSV2, VZV and HCMV several resistance mutations within the finger domain associated with region VI within helix PA and region III within helix PB. Helix PA and PB are equivalent to helix N and P of RB69gp43 (Figure 2) [32,33]. These two regions make up the finger domain contribution to the polymerase active site. Helix $\mathrm{N}$ contains several conserved residues important for nucleotide binding, while Helix $\mathrm{P}$ contains conserved residue K560 that is required for proton transfer during catalysis and N564, which is 
required for nucleotide binding. Crystal structures of RB69gp43 have shown that residue N564 interacts with the $\beta$ phosphate of the nucleotide via a water molecule $[52,63]$. There are also several resistance mutations associated with the motif A, C and KKRY within the palm domain (Appendix Figure A1). In Motif $A$ or region II there are several mutations prior to Motif $A$, which cause a pyrophosphate inhibitor hypersensitive, nucleotide inhibitor resistance phenotype. Mutations in motif $\mathrm{C}$ or region I and the KKRY motif or region VII (Appendix Figure A1) have all been characterized as inducing both pyrophosphate and nucleotide inhibitor resistance. Being that motif $\mathrm{C}$ and the KKRY motif is involved in aligning the $3^{\prime}-\mathrm{OH}$ nucleophile during catalysis any subtle change to the positioning of these motifs could change the binding and catalytic constants of the polymerase.

Several mutations remain to be confirmed as resistance-conferring amino acid substitutions [33]. Because of the difficulties in working with herpesviridae these mutations have not been tested in a defined genetic background to determine the phenotypic effect on resistance or susceptibility.

\section{Conclusions}

RB69gp43 provides an excellent model for the study of structure-function relationships of B family polymerases. However, there are limitations for the study of orthologous herpesviridae polymerases. Most importantly, the phage enzyme is not inhibited by approved drugs that bind to the polymerase active site in either post- or pre-translocational states. Chimeric enzymes composed of a RB69gp43 backbone and important elements of the active site of herpesviridae DNA polymerases can potentially address this problem. These findings warrant further investigation in such enzymes as novel tools in future drug discovery and development efforts.

\section{Acknowledgments}

M.G. is the recipient of a career award from the Fonds de la recherche en santé du Québec (FRSQ). This work was supported by funds from the Québec Consortium for Drug Discovery (CQDM).

\section{Conflict of Interest}

The authors declare no conflict of interest.

\section{References and Notes}

1. Elion, G.B.; Furman, P.A.; Fyfe, J.A.; de Miranda, P.; Beauchamp, L.; Schaeffer, H.J. Selectivity of action of an antiherpetic agent, 9-(2-hydroxyethoxymethyl) guanine. Proc. Natl. Acad. Sci. U. S. A. 1977, 74, 5716-5720.

2. Ertl, P.F.; Thomas, M.S.; Powell, K.L. High level expression of DNA polymerases from herpesviruses. J. Gen. Virol. 1991, 72, 1729-1734.

3. Tsurumi, T.; Kobayashi, A.; Tamai, K.; Daikoku, T.; Kurachi, R.; Nishiyama, Y. Functional expression and characterization of the epstein-barr virus DNA polymerase catalytic subunit. J. Virol. 1993, 67, 4651-4658.

4. Lin, J.C.; De, B.K.; Mar, E.C. Functional characterization of partially purified epstein-barr virus DNA polymerase expressed in the baculovirus system. Virus Genes 1994, 8, 231-241. 
5. Tsurumi, T.; Daikoku, T.; Nishiyama, Y. Further characterization of the interaction between the epstein-barr virus DNA polymerase catalytic subunit and its accessory subunit with regard to the 3'-to-5' exonucleolytic activity and stability of initiation complex at primer terminus. J. Virol. 1994, 68, 3354-3363.

6. De Bolle, L.; Manichanh, C.; Agut, H.; De Clercq, E.; Naesens, L. Human herpesvirus 6 DNA polymerase: Enzymatic parameters, sensitivity to ganciclovir and determination of the role of the a961v mutation in hhv-6 ganciclovir resistance. Antivir. Res. 2004, 64, 17-25.

7. Picard-Jean, F.; Bougie, I.; Bisaillon, M. Characterization of the DNA- and dntp-binding activities of the human cytomegalovirus DNA polymerase catalytic subunit ul54. Biochem. J. 2007, 407, 331-341.

8. Dorjsuren, D.; Badralmaa, Y.; Mikovits, J.; Li, A.Q.; Fisher, R.; Ricciardi, R.; Shoemaker, R.; Sei, S. Expression and purification of recombinant kaposi's sarcoma-associated herpesvirus DNA polymerase using a baculovirus vector system. Protein Expr. Purif. 2003, 29, 42-50.

9. Liu, S.; Knafels, J.D.; Chang, J.S.; Waszak, G.A.; Baldwin, E.T.; Deibel, M.R., Jr.; Thomsen, D.R.; Homa, F.L.; Wells, P.A.; Tory, M.C.; et al. Crystal structure of the herpes simplex virus 1 DNA polymerase. J. Biol. Chem. 2006, 281, 18193-18200.

10. Ducancelle, A.; Gravisse, J.; Alain, S.; Fillet, A.M.; Petit, F.; Pors, M.J.; Mazeron, M.C. Phenotypic characterisation of cytomegalovirus DNA polymerase: A method to study cytomegalovirus isolates resistant to foscarnet. J. Virol. Meth. 2005, 125, 145-151.

11. Tchesnokov, E.P.; Gilbert, C.; Boivin, G.; Gotte, M. Role of helix p of the human cytomegalovirus DNA polymerase in resistance and hypersusceptibility to the antiviral drug foscarnet. J. Virol. 2006, 80, 1440-1450.

12. Mueser, T.C.; Hinerman, J.M.; Devos, J.M.; Boyer, R.A.; Williams, K.J. Structural analysis of bacteriophage 4 DNA replication: A review in the virology journal series on bacteriophage $\mathrm{t} 4 \mathrm{and}$ its relatives. Virol. J. 2010, 7, 359.

13. Wang, J.; Sattar, A.K.; Wang, C.C.; Karam, J.D.; Konigsberg, W.H.; Steitz, T.A. Crystal structure of a pol alpha family replication DNA polymerase from bacteriophage rb69. Cell 1997, 89, 1087-1099.

14. Yang, G.; Lin, T.; Karam, J.; Konigsberg, W.H. Steady-state kinetic characterization of rb69 DNA polymerase mutants that affect dntp incorporation. Biochemistry 1999, 38, 8094-8101.

15. Franklin, M.C.; Wang, J.; Steitz, T.A. Structure of the replicating complex of a pol alpha family DNA polymerase. Cell 2001, 105, 657-667.

16. Hogg, M.; Wallace, S.S.; Doublie, S. Crystallographic snapshots of a replicative DNA polymerase encountering an abasic site. EMBO J. 2004, 23, 1483-1493.

17. Garcia-Diaz, M.; Bebenek, K. Multiple functions of DNA polymerases. Crit. Rev. Plant Sci. 2007, 26, 105-122.

18. Braithwaite, D.K.; Ito, J. Compilation, alignment, and phylogenetic relationships of DNA polymerases. Nucleic Acids Res. 1993, 21, 787-802.

19. Garg, P.; Burgers, P.M. DNA polymerases that propagate the eukaryotic DNA replication fork. Crit. Rev. Biochem. Mol. Biol. 2005, 40, 115-128.

20. De Waard, A.; Paul, A.V.; Lehman, I.R. The structural gene for deoxyribonucleic acid polymerase in bacteriophages t4 and t5. Proc. Natl. Acad. Sci. U. S. A. 1965, 54, 1241-1248. 
21. Goulian, M.; Lucas, Z.J.; Kornberg, A. Enzymatic synthesis of deoxyribonucleic acid. Xxv. Purification and properties of deoxyribonucleic acid polymerase induced by infection with phage t4. J. Biol. Chem. 1968, 243, 627-638.

22. Kornberg, A. Active center of DNA polymerase. Science 1969, 163, 1410-1418.

23. Schrodinger, L.L.C. The Pymol Molecular Graphics System, version 1.3r1; Schrödinger K.K.; http://www.pymol.org/, 2010.

24. Drummond, A.; Ashton, B.; Buxton, S.; Cheung, M.; Cooper, A.; Duran, C.; Field, M.; Heled, J.; Kearse, M.; Markowitz, S.; et al. Geneious v5.4; Biomatters Ltd; http://www.geneious.com/, 2010

25. Edgar, R.C. Muscle: Multiple sequence alignment with high accuracy and high throughput./Zh Nucleic Acids Res. 2004, 32, 1792-1797.

26. Mosca, R.; Brannetti, B.; Schneider, T.R. Alignment of protein structures in the presence of domain motions. BMC Bioinformatics 2008, 9, 352.

27. Hwang, C.B.; Ruffner, K.L.; Coen, D.M. A point mutation within a distinct conserved region of the herpes simplex virus DNA polymerase gene confers drug resistance. J. Virol. 1992, 66, 1774-1776.

28. Wong, S.W.; Wahl, A.F.; Yuan, P.M.; Arai, N.; Pearson, B.E.; Arai, K.; Korn, D.; Hunkapiller, M.W.; Wang, T.S. Human DNA polymerase alpha gene expression is cell proliferation dependent and its primary structure is similar to both prokaryotic and eukaryotic replicative DNA polymerases. EMBO J. 1988, 7, 37-47.

29. Zhang, J.; Chung, D.W.; Tan, C.K.; Downey, K.M.; Davie, E.W.; So, A.G. Primary structure of the catalytic subunit of calf thymus DNA polymerase delta: Sequence similarities with other DNA polymerases. Biochemistry 1991, 30, 11742-11750.

30. Simon, M.; Giot, L.; Faye, G. The 3' to 5' exonuclease activity located in the DNA polymerase delta subunit of saccharomyces cerevisiae is required for accurate replication. EMBO J. 1991, 10, 2165-2170.

31. Blanco, L.; Bernad, A.; Blasco, M.A.; Salas, M. A general structure for DNA-dependent DNA polymerases. Gene 1991, 100, 27-38.

32. Gilbert, C.; Bestman-Smith, J.; Boivin, G. Resistance of herpesviruses to antiviral drugs: Clinical impacts and molecular mechanisms. Drug Resist. Updates 2002, 5, 88-114.

33. Lurain, N.S.; Chou, S. Antiviral drug resistance of human cytomegalovirus. Clin. Microbiol. Rev. 2010, 23, 689-712.

34. Terrell, S.L.; Coen, D.M. The pre-nh2-terminal domain of the herpes simplex virus 1 DNA polymerase catalytic subunit is required for efficient viral replication. J. Virol. 2012, 86, 11057-11065.

35. Burd, C.G.; Dreyfuss, G. Conserved structures and diversity of functions of rna-binding proteins. Science 1994, 265, 615-621.

36. Hughes, M.B.; Yee, A.M.; Dawson, M.; Karam, J. Genetic mapping of the amino-terminal domain of bacteriophage t4 DNA polymerase. Genetics 1987, 115, 393-403.

37. Hogg, M.; Rudnicki, J.; Midkiff, J.; Reha-Krantz, L.; Doublie, S.; Wallace, S.S. Kinetics of mismatch formation opposite lesions by the replicative DNA polymerase from bacteriophage rb69. Biochemistry 2010, 49, 2317-2325. 
38. Xia, S.; Wang, M.; Blaha, G.; Konigsberg, W.H.; Wang, J. Structural insights into complete metal ion coordination from ternary complexes of b family rb69 DNA polymerase. Biochemistry 2011, 50, 9114-9124.

39. Castro, C.; Smidansky, E.D.; Arnold, J.J.; Maksimchuk, K.R.; Moustafa, I.; Uchida, A.; Gotte, M.; Konigsberg, W.; Cameron, C.E. Nucleic acid polymerases use a general acid for nucleotidyl transfer. Nat. Struct. Mol. Biol. 2009, 16, 212-218.

40. Bebenek, A.; Dressman, H.; Carver, G.; Ng, S.; Petrov, V.; Yang, G.; Konigsberg, W.; Karam, J.; Drake, J. Interacting fidelity defects in the replicative DNA polymerase of bacteriophage rb69. J. Biol. Chem. 2001, 276, 10387-10397.

41. Steitz, T.A. A mechanism for all polymerases. Nature 1998, 391, 231-232.

42. Castro, C.; Smidansky, E.; Maksimchuk, K.R.; Arnold, J.J.; Korneeva, V.S.; Gotte, M.; Konigsberg, W.; Cameron, C.E. Two proton transfers in the transition state for nucleotidyl transfer catalyzed by rna- and DNA-dependent rna and DNA polymerases. Proc. Natl. Acad. Sci. U. S. A. 2007, 104, 4267-4272.

43. Fothergill, M.; Goodman, M.F.; Petruska, J.; Warshel, A. Structure-energy analysis of the role of metal-ions in phosphodiester bond hydrolysis by DNA-polymerase-i. J. Am. Chem. Soc. 1995, 117, 11619-11627.

44. Patel, S.S.; Wong, I.; Johnson, K.A. Pre-steady-state kinetic analysis of processive DNA replication including complete characterization of an exonuclease-deficient mutant. Biochemistry 1991, 30, 511-525.

45. Wong, I.; Patel, S.S.; Johnson, K.A. An induced-fit kinetic mechanism for DNA replication fidelity: Direct measurement by single-turnover kinetics. Biochemistry 1991, 30, 526-537.

46. Drake, J.W. A constant rate of spontaneous mutation in DNA-based microbes. Proc. Natl. Acad. Sci. U. S. A. 1991, 88, 7160-7164.

47. Shamoo, Y.; Steitz, T.A. Building a replisome from interacting pieces: Sliding clamp complexed to a peptide from DNA polymerase and a polymerase editing complex. Cell 1999, 99, 155-166.

48. Aller, P.; Duclos, S.; Wallace, S.S.; Doublie, S. A crystallographic study of the role of sequence context in thymine glycol bypass by a replicative DNA polymerase serendipitously sheds light on the exonuclease complex. J. Mol. Biol. 2011, 412, 22-34.

49. Hogg, M.; Aller, P.; Konigsberg, W.; Wallace, S.S.; Doublie, S. Structural and biochemical investigation of the role in proofreading of a beta hairpin loop found in the exonuclease domain of a replicative DNA polymerase of the b family. J. Biol. Chem. 2007, 282, 1432-1444.

50. Zhang, H.; Beckman, J.; Wang, J.; Konigsberg, W. Rb69 DNA polymerase mutants with expanded nascent base-pair-binding pockets are highly efficient but have reduced base selectivity. Biochemistry 2009, 48, 6940-6950.

51. Yang, G.; Franklin, M.; Li, J.; Lin, T.C.; Konigsberg, W. A conserved tyr residue is required for sugar selectivity in a pol alpha DNA polymerase. Biochemistry 2002, 41, 10256-10261.

52. Yang, G.; Franklin, M.; Li, J.; Lin, T.C.; Konigsberg, W. Correlation of the kinetics of finger domain mutants in rb69 DNA polymerase with its structure. Biochemistry 2002, 41, 2526-2534.

53. Zhang, H.; Rhee, C.; Bebenek, A.; Drake, J.W.; Wang, J.; Konigsberg, W. The 1561a substitution in the nascent base-pair binding pocket of rb69 DNA polymerase reduces base discrimination. Biochemistry 2006, 45, 2211-2220. 
54. Reha-Krantz, L.J.; Wong, C. Selection of bacteriophage $t 4$ antimutator DNA polymerases: A link between proofreading and sensitivity to phosphonoacetic acid. Mutat. Res. 1996, 350, 9-16.

55. Reha-Krantz, L.J.; Nonay, R.L.; Stocki, S. Bacteriophage t4 DNA polymerase mutations that confer sensitivity to the ppi analog phosphonoacetic acid. J. Virol. 1993, 67, 60-66.

56. Zhong, X.; Pedersen, L.C.; Kunkel, T.A. Characterization of a replicative DNA polymerase mutant with reduced fidelity and increased translesion synthesis capacity. Nucleic Acids Res. 2008, 36, 3892-3904.

57. Li, V.; Hogg, M.; Reha-Krantz, L.J. Identification of a new motif in family b DNA polymerases by mutational analyses of the bacteriophage t4 DNA polymerase. J. Mol. Biol. 2010, 400, 295-308.

58. Tchesnokov, E.P.; Obikhod, A.; Schinazi, R.F.; Gotte, M. Engineering of a chimeric rb69 DNA polymerase sensitive to drugs targeting the cytomegalovirus enzyme. J. Biol. Chem. 2009, 284, 26439-26446.

59. Zahn, K.E.; Tchesnokov, E.P.; Götte, M.; Doublié, S. Phosphonoformic acid inhibits viral replication by trapping the closed form of the DNA polymerase. J. Biol. Chem. 2011, 286, 25246-25255.

60. Landry, M.L.; Stanat, S.; Biron, K.; Brambilla, D.; Britt, W.; Jokela, J.; Chou, S.; Drew, W.L.; Erice, A.; Gilliam, B.; et al. A standardized plaque reduction assay for determination of drug susceptibilities of cytomegalovirus clinical isolates. Antimicrob. Agents Chemother. 2000, 44, 688-692.

61. Kuhn, F.J.; Knopf, C.W. Herpes simplex virus type 1 DNA polymerase. Mutational analysis of the 3'-5'-exonuclease domain. J. Biol. Chem. 1996, 271, 29245-29254.

62. Hwang, Y.T.; Smith, J.F.; Gao, L.; Hwang, C.B. Mutations in the exo iii motif of the herpes simplex virus DNA polymerase gene can confer altered drug sensitivities. Virology 1998, 246, 298-305.

63. Wang, M.; Xia, S.; Blaha, G.; Steitz, T.A.; Konigsberg, W.H.; Wang, J. Insights into base selectivity from the 1.8 a resolution structure of an rb69 DNA polymerase ternary complex. Biochemistry 2011, 50, 581-590. 
Appendix Figure A1. Protein sequence alignment of herpesvirus and bacteriophage polymerases based on structural data. Herpesvirus and bacteriophage polymerase were aligned individually using the muscle algorithm within Geneious [24,25]. Then the bacteriophage and herpesvirus sequences were aligned using an alignment based on a structural alignment of HSV1 UL30 (2GV9) and RB69 gp43 (1IH7) produced by RAPIDO [26]. Blocks above sequence highlight structural domains of polymerase. Regions unresolved in the HSV1 structural model are shown in green. The pre $\mathrm{N}$ terminal domain is in white. The $\mathrm{N}$ terminal domain is in yellow. The 3'-5' exonuclease domain is in red. The palm domain is in pink. The fingers domain is in blue and thumb domain is in green. The known conserved regions are shown in magenta blocks above sequence [27-31]. Secondary structural elements of HSV1 UL30 are indicated. Elements are number according scheme provided in Liu et al. (2006). Secondary Structural elements of RB69 gp43 are indicated. Elements are numbered according scheme provided in Wang et al. (1997). Structural motifs involved in polymerase and exonuclease activity are highlighted in sequence. Herpes virus specific motif is in blue. Exonuclease conserved residues are in red. Motif $\mathrm{A}$ is in magenta. $\mathrm{N}$ helix residues are in yellow. Motif B is in green. Motif $\mathrm{C}$ is in brown. KKRY motif is in purple. Mutations that have been associated with resistance to anti-herpetic drugs are shown below the corresponding residue [32,33]. Resistance conferring mutations are colored using the following scheme: Red: Pyrophosphate ${ }^{\mathrm{R}}$ (Resistant), Blue: Nucleotide ${ }^{\mathrm{R}}$, Green: Pyrophosphate ${ }^{\mathrm{R}}$ and Nucleotide $^{\mathrm{R}}$. Purple: Pyrophosphate ${ }^{\mathrm{HS}}$ (Hypersensitive). Pink: Pyrophosphate ${ }^{\mathrm{R}}$ but Nucleotide $^{\mathrm{HS}}$, Brown: Nucleotide ${ }^{\mathrm{R}}$ but Pyrophosphate ${ }^{\mathrm{HS}}$. 
Appendix Figure A1. Cont.

HSV1 UL30

HSV2 UL30

VZV ORF28

EBV BALF 5

HCMV UL54

HHV 6 U38

HHV 7 U38

KSHV ORF 9

T4 gp 43

RB69 gp43
Not Visible

Pre N Terminal

1 MFSGGGGPLSPGGKSAARAASGFFAPAGPRGAS-RGPPPCLRQNF YNPYLAPVGTQQKPTGPTQR------HTYYSECDE-FRF IAPRVLDEDAPPEKRA 92 1 MFCAAGGPASPGGKPAARAASGF FAPHNPRGATQTAPPPCRRQNF YNPHLAQTGTQPKALGPAQR------HTYYSECDE-FRF IAPRSLDEDAPAEQRT 93 $1--------------------------$ MAIRTGF CNPF LTQASGIKYNPRTGRGSNREF LHSYKT TMSS-FQF LAPKCLDEDV PMEERK 61 $1-------------------------------M S G G L F Y N P F$ LR ------------------------- PNKGLLKKPDKE YLRLIPKC 32

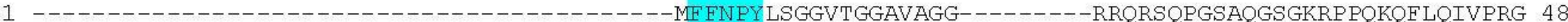

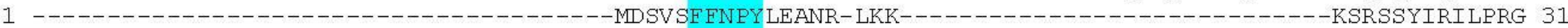
$1--------------------------------M D L V S E F N P Y$ LENVRT-KK-------------------------- KTKSTELRIFPRG 31

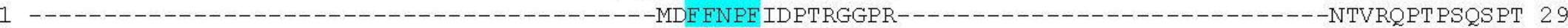
- - - - - --- - - -

Herpes Specific Motif

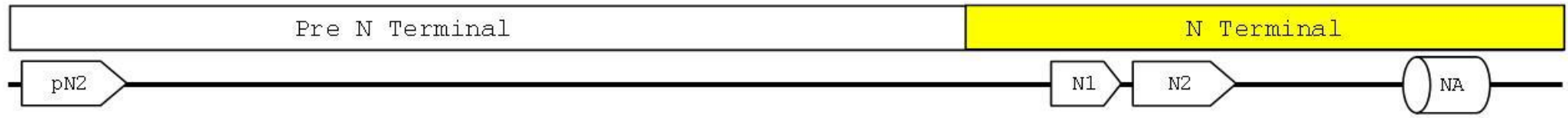

HSV1 UL30

HSV2 UL30

VZV ORF28

EBV BALF 5

HCMV UL54

HHV 6 U38

HHV7 U38

KSHV ORF 9

T4 gro 43

RB69 gro43

93 GVHDGHLKR---A----P---KVYCGGDERDVLRVGS---GGFWPRRSRLWGGVDH-APAGFNPTVTVFHVYDILENVEHAYGMRAAOFHARFMDAITPT 178 94 GVHDGRLRR---A----P---KVYCGGDERDVLRVGP---EGFWPRRLRLWGGADH-APEGFDPTVTVFHVYDILEHVEHAYSMRAAQLHERFMDAIT PA 179 62 GVHVGTLSR--------P--PKVYCNGKEVPILDFRC---SSPWPRRVNIWGEIDF-RGDKFDPRFNTFHVYDIVETTEAASNGDVS----RFATATRPL 143 33 FQTPGAAGV---VDVRGPQ--PPLCFYQDSLTVVGGDEDGKGMWWRQRAQEGTAR--PEADTHGSPLDFHVYDILETVYTHEKCAVIPS--DKQGYVVPC 123 48 VMFDGQTGL----------I---KHKTGRLPLMFYRE---IKHLLSHDMVWPCPWRETLVGRVVGPIRFHTYDQTDAVLFEDSPENVSP--RYRQHLVPS 130 31 IMHDGAAGL-----I------KDVCDSEPR--MFYRD---RQYLLSKEMTWPSLDRVRSKDYDHTRMKFHIYDAVETLMFTDSIENLPF--QYRHFVIPS 113 31 IMHDGAPGLM----K------TLCDSEPR--MFYQD---KQYILKNDMTWPSLSOVAEKELR-APLKFHIYDASESLLFTDSIENIPF--QYRHFVIPS 112 29 VPSETRVCRLIPACFQTPGRPGVVAVDTTFPPTYFQGPKRGEVFAGETGSIWKTRRGQARNAPMSHLIFHVYDIVETTYTADRCEDVPFS--FQTDIIPS 127 1 -

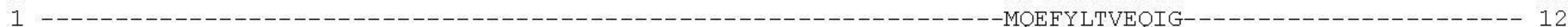

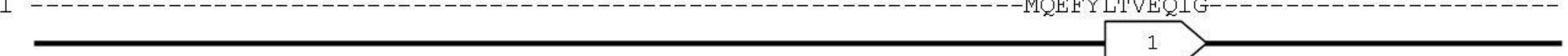


Appendix Figure A1. Cont.

N3

HSV1 UL30 179 GTVITLLGLTP-EGHRVAVHVYGTRQYFYMNKEEVDRHLQCRAPRDLCERMAAALRES---------------PGASFRGISADHFEAEVVERTDVYYY 261

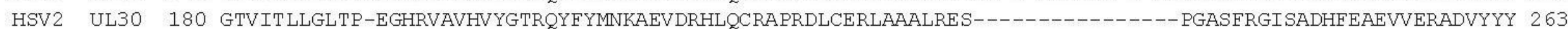

VZV ORF28 144 GTVITLLGMSR-CGKRVAVHVYGICQYFYINKAEVDTACGIRSGSELSVLLAECLRSSMITQNDATLNGDKNAFHGTSFKSASPESFRVEVIERTDVYYY 242 EBV BALF 5124 GIVIKLLGRRKADGASVCVNVFGQQAYFY---------ASAPOGLDVEFAVLSALKAS------------------TFDRRTPCRVSVEKVTRRSIMGY 195

HCMV UL5 4131 GNVLRFFGATE-HGYSICVNVFGQRSYFY---------CEYSDTDRLREVIASVGELVP-------------------EPRTPYAVSVTPATKTSIYGY 200

HHV 6 U38 114 GTVIRMFGRSE-DGEKICVNVFGQEQYFY---------CECVDGKSLKATINNLMLTG---------------------EVKMSCSFVIEPADKLSLYGY 182

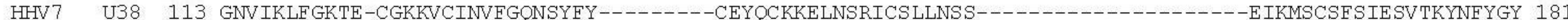
KSHV ORF 9128 GTVLKLLGRTL-DGASVCVNVFRQRCYFY---------TLAPQGVNLTHVLQQALQAG---------------------FGRASCGFSTEPVRKKILRAY 196 T4 gP43 13 NNIVERYIDEN--GKERTREVE-YLPTMF RHCKE--------------------------------------------------ES--KYKD 49

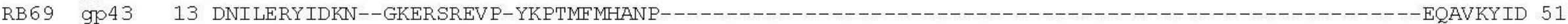

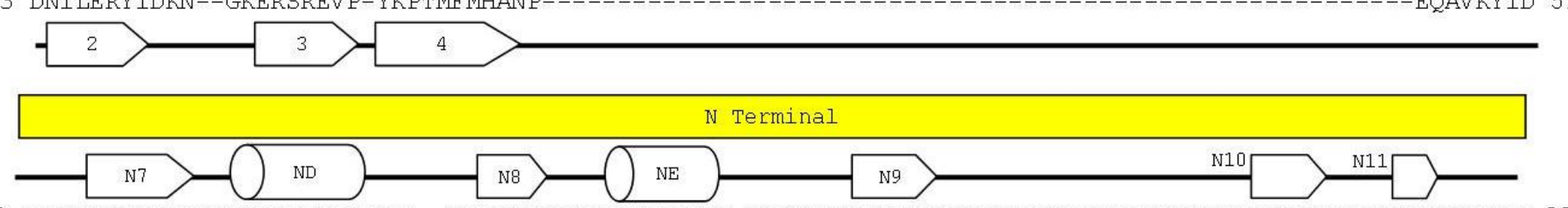

HSV1 UL30 262 ETRPALFYRVYVRSGRVLSYLCDNFC--PAIKKYEGGVDATTRFILD-NPGFVTFGWYRLKPGRNNTLAQPAAPMAFGTSSDVEFNCTADNLAIEGGMSD 358 HSV2 UL30 264 ETRPTLYYRVFVRSGRALAYLCDNFC--PAIRKYEGGVDATTRFILD-NPGFVTFGWYRLKPGRGNAPAQPRPPTAFGTSSDVEFNCTADNLAVEGAMCD 359

VZV ORF28 243 DTQPCAFYRVYSPSSKFTNYLCDNF--HPELKKYEGRVDATTRFLMD-NPGFVSFGWYQLKPGVDGERVRVRPASRQLTLSDVEIDCMSDNLQAIPNDDS 339

EBV BALF 5196 GNHAGDYHKITLSHPNSVCHVATWLQDKHGCRIFEANVDATRRFVLD-N-DFVTFGWYSCRRAIPRLQHRD-------SYAELEYDCEVGDLSVRREDSS 286

HCMV UL54 201 GTRPVPDLQCVSISNWTMARKIGEYLLEQGF PVYEVRVDPLTRLVID-RR-ITTFGWCSVNRYDWRQQGRAS-------TCDIEVDCDVSDLVAVPDDSS 291

HHV 6 U38 183 NANTVVNLFKVSFGNFYVSQRIGKILQNEGFVVYEIDVDVLTRFFVD-N-GF LSFGWYNVKKYIPQDMGKG-------SNLEVE INCHVSDLVSL-ENVN 272

HHV7 U38 182 NTEPIKNLFKLSF SNFYISNRIGKILLNEGVSVYEAEVEILNRFF ID-N-NLKSFGWYQINYLSIQEFAKS-------SNVEIELNCHVSDLFLLKED-S 271

KSHV ORF 9197 DTQQYAVOKITLSSSPMMRTLSDRLTT-CGCEVFESNVDAIRRFVLD-H-GFSTFGWYECSNPAPRTQARDS-------WTELEFDCSWEDLKF IPERTE 286

T4 gP43 50 IYGKNCAPQKF PSMKDARDWMKRMED--IGLEALG-MNDFKLAYISDTYGSEI-----------------------------------------VYD 102

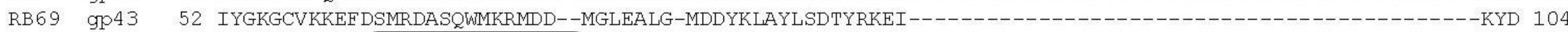

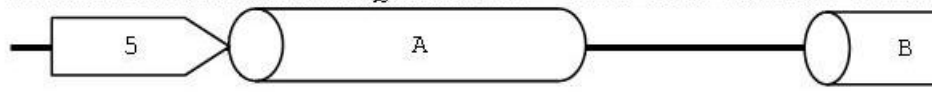


Appendix Figure A1. Cont.

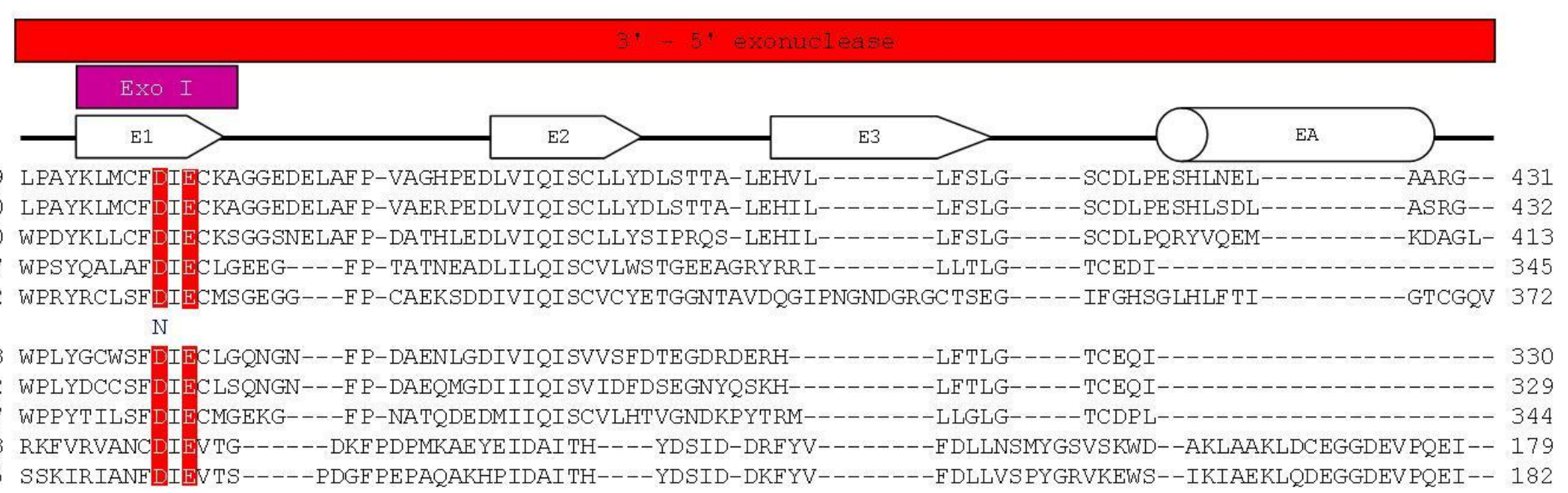

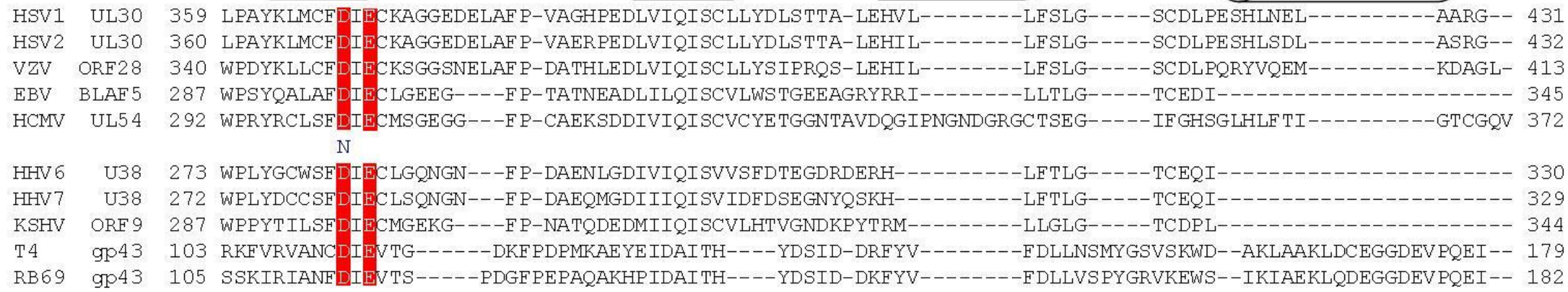

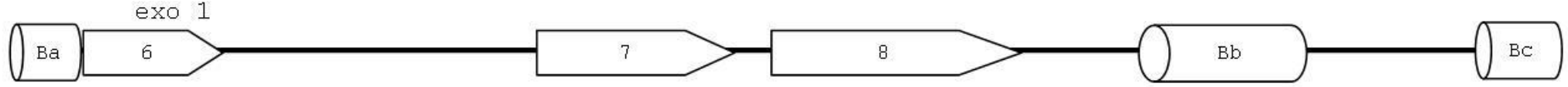


Appendix Figure A1. Cont.

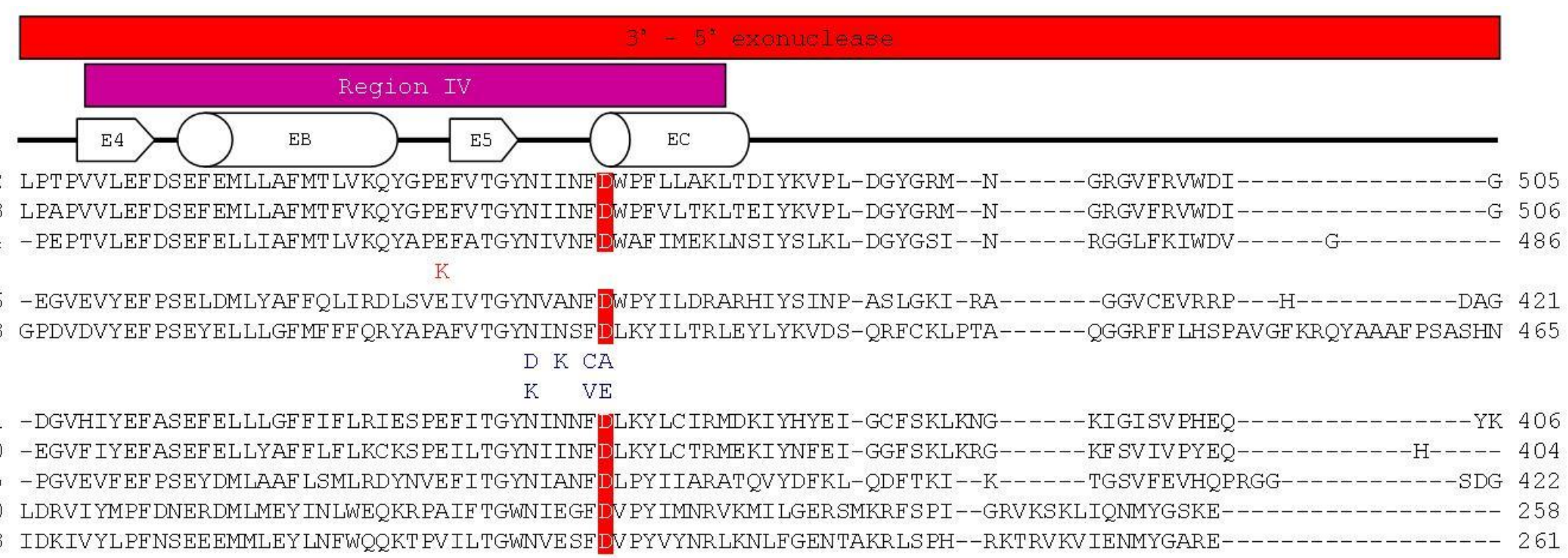

HSV1 UL30

VZV ORF28

EBV BLAF 5

HCMV UL5 4

HHV 6

$\mathrm{HH} 7$

KSHV

T4

RB69

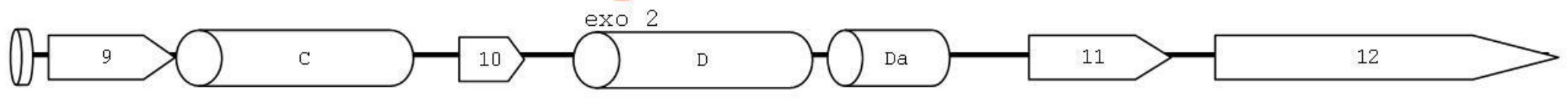


Appendix Figure A1. Cont.

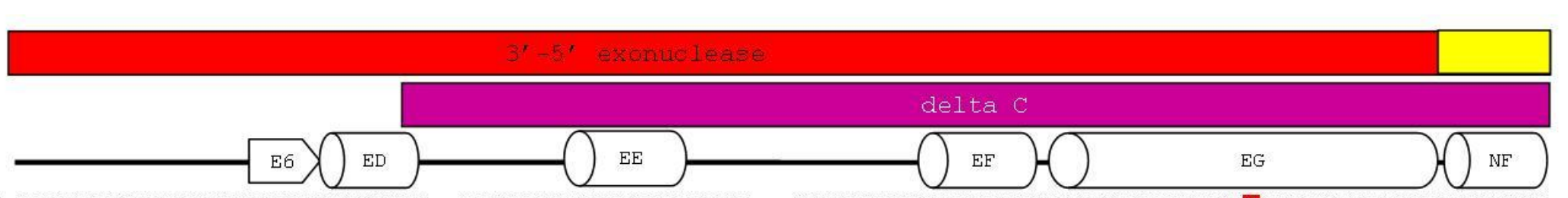

HSV1 UL30 506 QSHFQKR.SKIKVNGMVNIDMYGIITDK--IKLSSYKLNAVAEAVLKDK---KKDLSY

HSV2 UL30 507 QSHFOKRSKIKVNGMVNIDMYGIITDK--VKLSSYKLNAVAEAVLKDK---KKDLSYRDIPAYYASGPAQRGVIGEYCVO

VZV ORF28 487 KSGFQRRSKVKINGLISLDMYAIATEK--LKLSSYKLDSVAREALNES---KRDLPYKDIPGYYASGPNTRGIIGEYCIQ

EBV BLAF 5422 KGF LRANTKVRITGLIPIDMYAVCRDK--LSLSDYKLDTVARHLLGAK---KEDVHYKE IPRLFAAGPEGRRRLGMYCVQ

HCMV UL54 466 NPASTAATKVYIAGSVVIDMY PVCMAK--TNSPNYKLNTMAELYLRQR---KDDLSYKDIPRCFVANAEGRAQVGRYCLQI $\mathrm{K}$

$$
\text { I I }
$$
$\mathrm{E} \quad \mathrm{R}$

$\mathrm{TA}$

HHV 6 U38 407 KGF LQAQTKVF TSGVLYLDMY PVYSSK--ITAQNYKLDT IAKICLQQE---KEQLSYKE IPKKFISGPSGRAVVGKYCLQDS HHV7 U38 405 KKF LNSLTKVNMSGILCFDMYNVYSSK--ISAQNYKLDT IAKLCLNQE---KKNLSYKE IPKKF IDGSKGRAVVGRYCIO

KSHV ORF 9423 GNFMRSQSKVKISGIVPIDMYQVCREK--LSLSDYKLDTVAKQCLGRQ---KDDISYKDIPPLFKSGPDGRAKVGNYCVI 
Appendix Figure A1. Cont.

\begin{tabular}{|c|c|}
\hline N Terminal & Non visible \\
\hline \hline delta C \\
\hline
\end{tabular}

HSV1 UL30 601 VARLAGINITRTIYDGQQIRVFTCLLRLADQKGFILPDTQ--GRFRGAGGEAPKRPAA----------------A-------------REDEERPEEEGE 669

HSV2 UL30 602 VARLAGINITRTIYDGQQIRVFTCLLRLAGQKGFILPDTQ--GRFRGLDKEAPKRPAV----------------P-------------RGEGERPGDGNG 670

VZV ORF28 582 VARLARITLTKAIYDGQQVRIYTCLLGLASSRGFILPDGGYPATFEYKDVIPDVGDVE--------------------------EEMDEDESVSPTGTSS 655

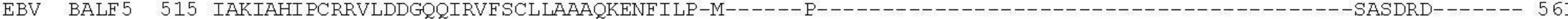

HCMV UL54 561 IARLAKIPLRRVIFDGOOIRIYTSLLDECACRDFILPNHYSKGTTVPETNSVAVSPNAAIISTAAVPGDAGSVAAMFOMSPPLOSAPSSODGVLPGSGSN 6 60 $\mathrm{N}$

HHV 6 U38 502 VARLAHVTARCVVEEGQQKKIFPCILTEAKRRNMILPSM------------------V-------------------------------SSHNRQG---- 548

HHV7 U38 498 VASLAYITIRCAVFEGQQKKIFPCILHEAKNLNMI LPSM------------------N--------------------------------TNFNKGKEN- 548

KSHV ORF 9518 IAKLAKIPTRRVLTDGQQIRVFSCLLEAAATEGYILPVP------------------K------------------------------GDAVS------ 562

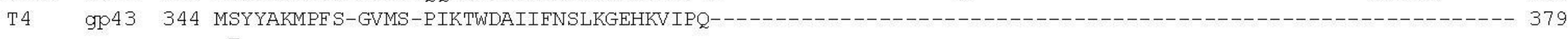
$\mathrm{F}$

RB69 gP43 347 MGYYAKMQIQ-SVFS-PIKTWDAIIFNSLKEQGRVIPQ--------------------------------------------------------- 382

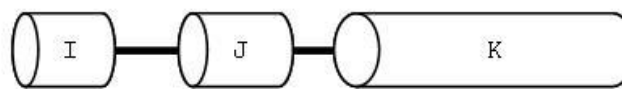


Appendix Figure A1. Cont.

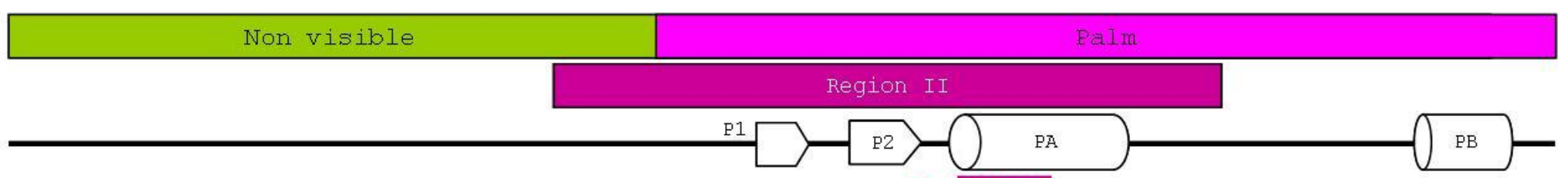

HSV1 UL30 670 DEDERE----EGGGERE PEGARETAGRH-------VGYQGARVLDPT SGFHVNPVVVHEFAELYR:

N

N

$Q$

$\mathrm{E}$

A

K

T

HSV2 UL30 671 DEDKDDDEDGDEDGDEREEVARETGGRH-------VGYQGARVLDPTSGFHVDPVVVFEFA $\mathrm{H}$

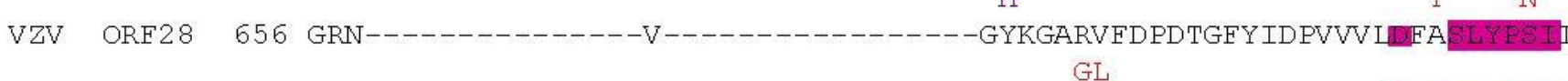

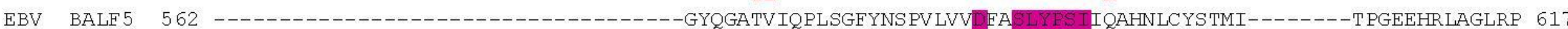

HCMV UL54 661 SSSSVGVFSVGSGSSGGVGVSNDSHGAGG---TAAVSYQGATVFEPEVGYYNDPVAVFLFA LLYPSIIMAHNLCYSTLL--------VPGGEYPV---DP 746

A $\quad$ A

HHV 6 U38 $549------------------------------$ IGYKGATVLEPKTGYYAVPTVNF

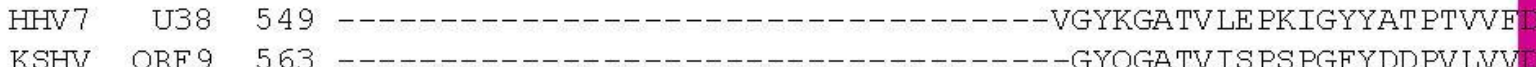

T4 gP43 $380---------------------Q$ QGSHVKQSFPGAFVFE PKPIAR-RYIMS F

RB69 gP43 383 ------------------------ARSHVVQPYPGAFVKEPI PNAY-KYVMSF

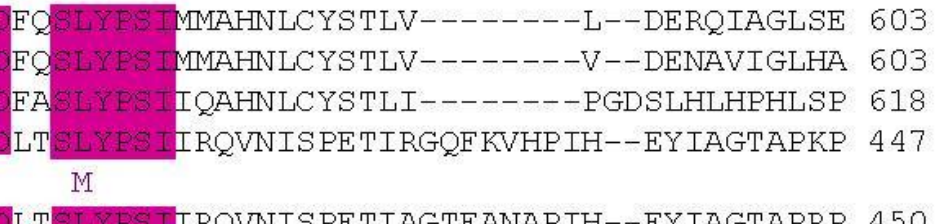

TSLYRS

RQVNISPETIAGTFANAPIH--EYIAGTAPRP 450 Motif A 
Appendix Figure A1. Cont.

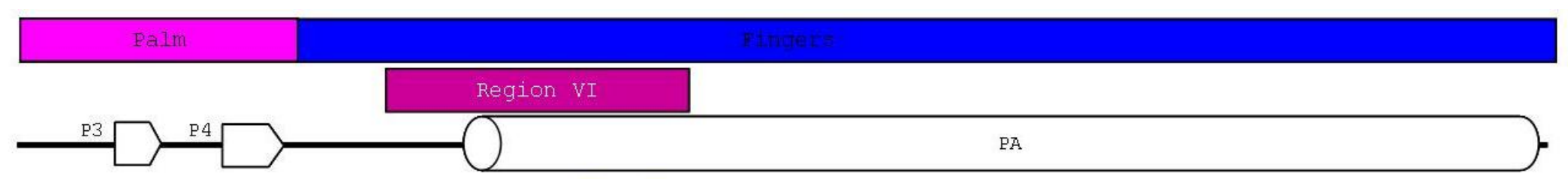

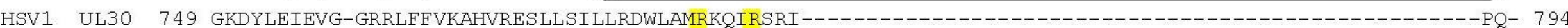

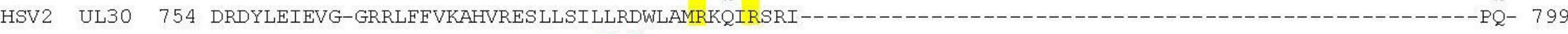
$\mathrm{M} \mathrm{N}$

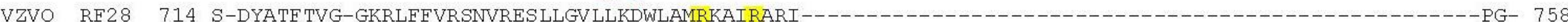

EBV BLAF 5618 GEDYESFRLT-GGVYHFVKKHVHESFLASLLTSWLAKRKAIKKLL------------------------------------------------AAC 664

HCMV UL54 747 ADVYSVTLEN-GVTHRFVRASVRVSVLSELLNKWVSQRRAVRECM----------------------------------------------------REC 793

K $M$ I I

$\mathrm{D}$

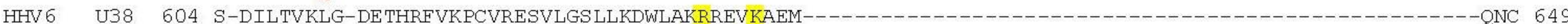

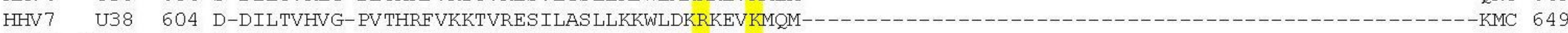

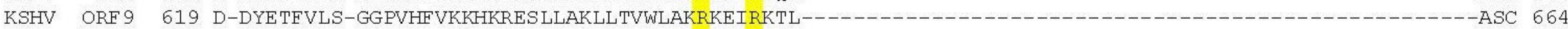

T4 gP43 448 SDEYSC---S-PNGWMYDK--HQEGII PKEIAKVF FQRKDWKKKMFAEEMNAEAIKKIIMKGAGSCSTKPEVERYVKF SDDF LNELSNYTESVLNSLIE- 540

RB69 9P43 451 SDVYSC---S-PNGMMYYK--DRDGVIPTEITKVFNQRKEHKGYMLAAQRNGELIKEALENPNLSVDSPLDIDYRFDF SDEIKAKIKT LSAPSLREMLF- 543

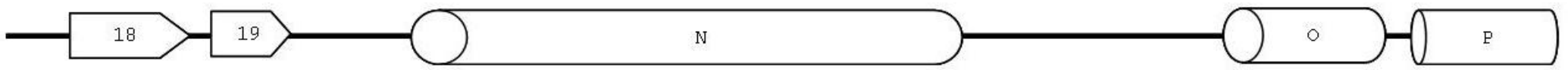


Appendix Figure A1. Cont.

HSV1 UL30

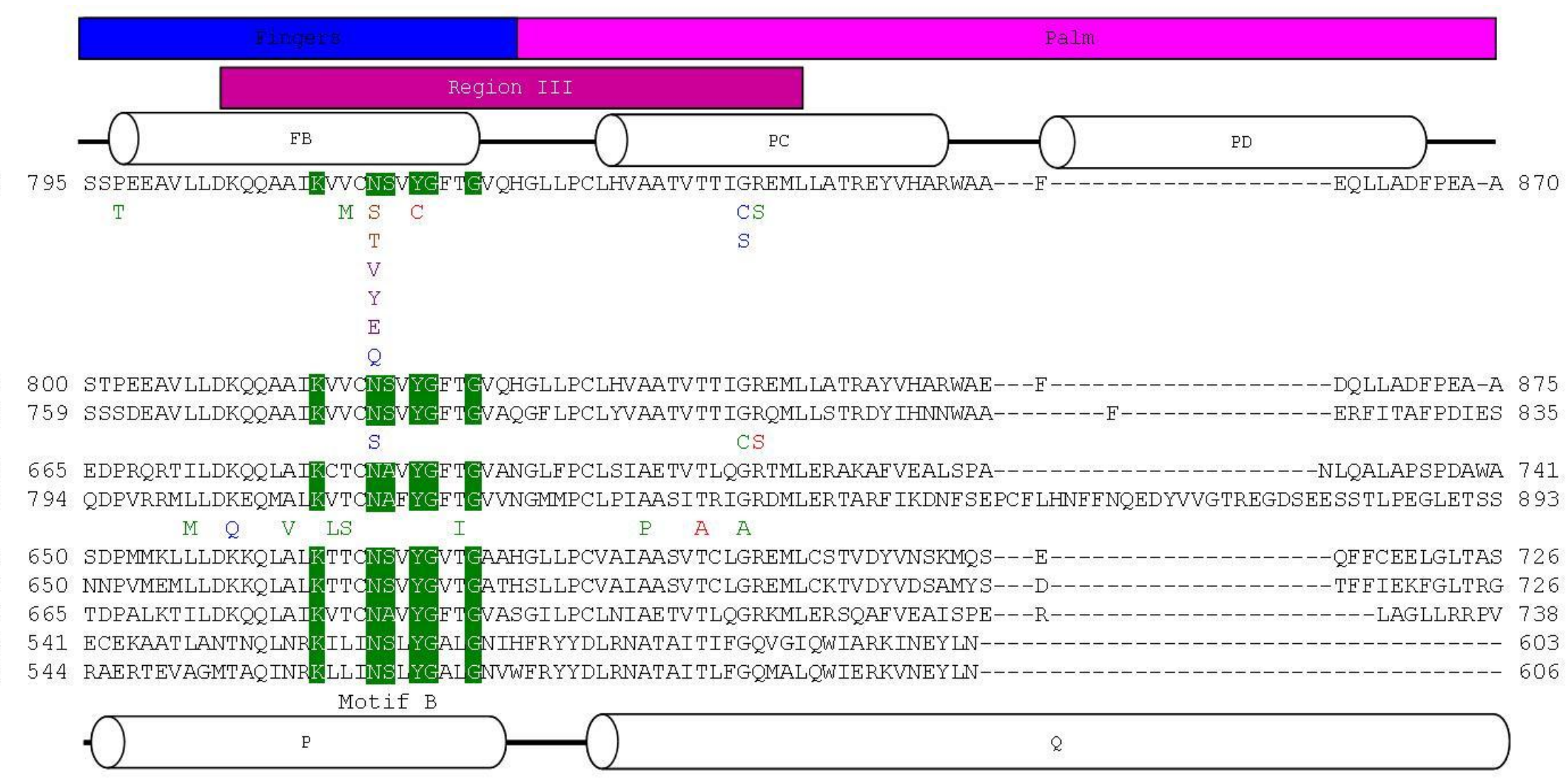


Appendix Figure A1. Cont.

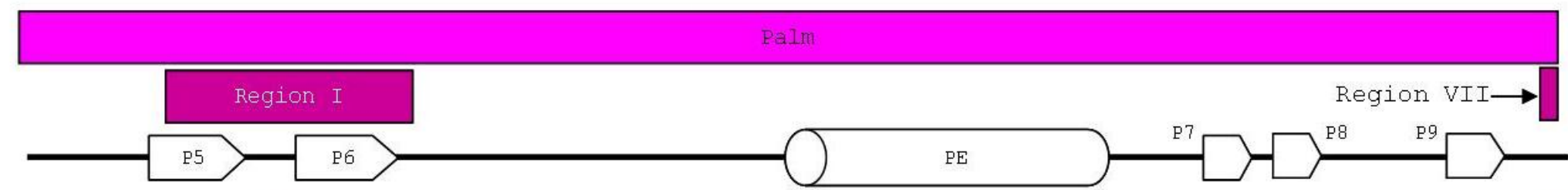

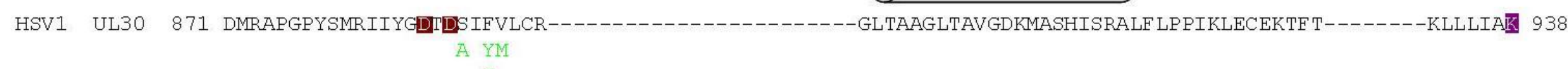

HSV2 UL30 876 GMRAPGPYSMRIIYGDIDSIFVLCR-----------------------GLTAAGLVAMGDKMASHISRALFLPPIKLECEKTFT--------KLLLIAR 943

VZV ORF28 836 SVLSQKAYEVKVIYGDIDSVFIRFK-----------------------GVSVEGIAKIGEKMAHIISTALFCPPIKLECEKTFI--------KLLLITK 903

EBV BALF 5742 PLNPEGQL--RVIYGDTDSLFIECR-----------------------GF SESETLRFAEALAAHTTRSLFVAPISLEAEKTFS--------CLMLITK 807

HCMV UL54 894 GGSDERRVEARVIYGDTDSVFVRFR-----------------------GLTPQALVARGPSLAHYVTACLFVEPVKLEFEKVFV--------SLMMICK 961

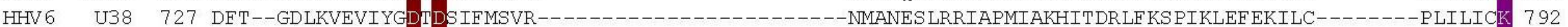

HHV7 U38 727 DFS--GTFGIEVIYGDTDSLFVTFK-----------------------NVCPKALKRIAPSIASHITNTLFKHPIKLEFEKILF--------PLILICK 792

KSHV ORF 9739 DVSPDARF--KVIYGDTDSLF ICCMGFNMDSVSDFAEELASITT------------------------NTLFRSPIKLEAEKIFK--------CLLLLTK 804

T4 9P43 604 -KVCGTNDEDF IAAGDTDSVYVCVDKVIEKVGLDRFKEQNDLVEFMNQFGKKKME PMIDVAYRELCDYMNNREHLMHMDREAISCP PLGSKGVGGFWKAK 702

RB69 9P43 607 -SVCKTENQKFVLYGDTDSIYVKADAI INKVGEDKFRDTNHWVDF LDKFARERME PAIDAGFREMCEYMNNKQHLMFMDREAIAGPPLGSKGLGGFWTGK 705

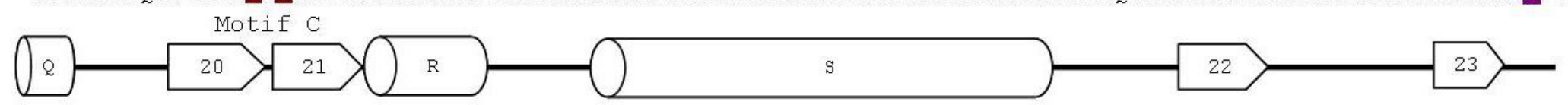


Appendix Figure A1. Cont.

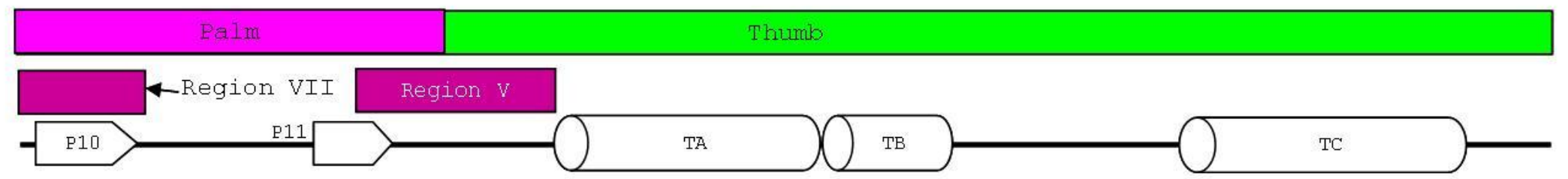

HSV1 UL30 939 KKYIGVIY-------GGKML-IKGVD-LVRKNNCAFINRTSRALVDLLFYDDTVSGAAAALAERPAEEWLARPLPEGLQAFGAVLVDAHRRITDPERDI 1300 $\mathrm{H}$ $\mathrm{K}$

HSV2 UL30 944 KKYIGVIC-------GGKML-IKGVD-LVRKNNCAFINRTSRALVDLLFYDDTVSGAAAALAERPAEEWLARPLPEGLOAFGAVLVDAHRRITDPERDI 1028 VZV ORF28 904

EBV BALF $5 \quad 808$

HCMV UL5 4962

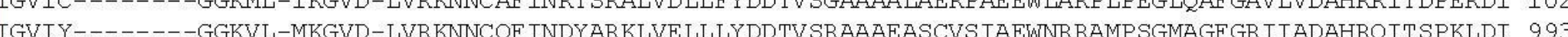

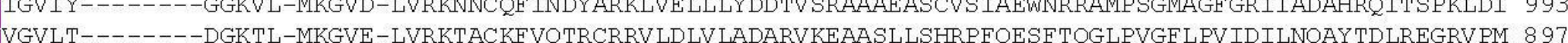
IGKVE-------GASGLSMKGVD-LVRKTACEFVKGVTRDVLSLLFEDREVSEAAVRLSRLSLDEVKKYGVPRGFWRILRRLVQARDDLYLHRVRV 1052 G

HHV $638 \quad 793$

HHV7 U38 793

KSHV ORF 9805

T4 gro43 703

RB69 g043 705

RYIGR-Q-------DDSLLIF KGVD-LVRKT SCDFVKGVVKDIVDLLFFDEEVQTAAVEFSHMTQTQLREQGVPVGIHKILRRLCKAREELFQNRADV 882 IGKL-------DDATLVFKGVE-LVRKT SCDFVKVVVKDIIDLLFWDVDVOKSAEKLSNMTIOEIYENGVPDGIOKIIKKLCDARDALF LNRVNI 882 VGVLS-------DDKVL-MKGVD-LIRKTACRFVQEKSSQVLDLILREPSVKAAAKLISGQATDWVYREGLPEGFVKIIQVLNASHRELCERSVPV 894 ALNVYDMEDKRF AE PHLK-IMGME TQQSST PKAVQEALEESIRRILQEGEE--------------SVQEYYKNE EKEYRQLDYKVIAEVKTANDIA 786 YALNVWDMEGTRYAE PHLK-IMGLETQKSST PKAVQKALKECIRRMLQEGEA--------------SLQEYFKQFNKEFNE LDYVSIAAVSSANNIE 7ZZ KKRY Motif 
Appendix Figure A1. Cont.

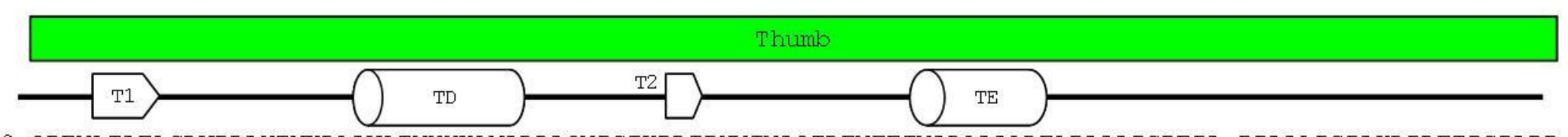

HSV1 UL30 1029 QDFVLTAELSRHPRAYTNKRLAHLTVYYKLMARRAQVPSIKDRIPYVIVAQTREVEE TVARLAALRELDAAAPGDE PA-PPAALPS PAKRPRETPSPADP 1127 HSV2 UL30 1034 QDFVLTAELSRHPRAYTNKRLAHLTVYYKLMARRAQVPSIKDRIPYVIVAQTREVEETVARLAALRELDAAAPGDE PA-PPAALPSPAKRPRETPSHADP 1132

VZV OFR28 994 NKFVMTAELSRPPSAYINRRLAHLTVYYKLVMRQGQI PNVRERIPYVIVAPTDEVE--------ADAKSVALLRGDPL----------------QNTAGK 1069

EBV BALF 598 GELCESTELSRKLSAYKSTQMPHLAVYQKFVERNEELPQIHDRIQYVFVEPKGGVKGAR-KTEMAEDPAYAERHGVPVAVDHYF DKLLQGAANI LQCLFD 996

HCMV UL5 1053 EDLVLSSVLSKDISLYRQSNLPHIAVIKRLAARSEELPSVGDRVFYVLTAPGVRTAPQ-GSSDHGDSVTTGVVSRSDAIDGTDDDADGGGVEESNRRGGE 1151

HHV6 U38 883 RHLMLSSVLSKEVAAYKQPNLAHLSVIRRLAQRKEEI PNVGDRIMYVLIAPSTGNKQTH-NYELAEDPNYVLEHKIPIHAEKYFDQIIKAVTNAISPIFP 981

HHV7 U38 883 KSLVLSSVLSKDISAYKQANLPHLAVVKRLAQRKEELPNIGDRVMYILIAPTE TVKKTFHNYELAEDPAYAIENNLKINADKYFEQIMKAVTNAISPIFP 982

KSHV ORF 9895 DKLTFTTELSRPLADYKTONL PHLTVYOKLOAROEELPOTHDRIPYVFVDAPGSLRS-----ELAEHPEYVKOHGLRVAVDLYFDKLVHAVANIIOCLFO 989

T4 gP43 787 KYDDKGWPGFKCPFHIRGVLTYRRAVSG-LGVAPILDGNKVMVLPLREGNPFGDKCIAWPSGTELPKE IRSDVLSWIDHSTLFQKSFVKPLAGMCESAGM 885

RB69 gP43 790 KYNEGGF PGSKCPYHIKGCLAYMRASAGDLTMPRIVDGEKVYVLPLKEGNPFGEACMAWPSGIELPVQIRDQVLRWMDYNVLFQKTEIKPLTGF TESAKI 889

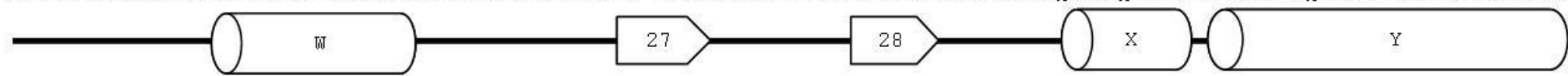


Appendix Figure A1. Cont.

\begin{tabular}{|l|l|l|}
\hline & Non Visible \\
\hline
\end{tabular}

HSV1 UL30 1128 PGGASKPRKLLV---SELAEDPAYAIAHGVALNTDYYFSHLLGAACVTFKALFGNNAKITESLLKRFIPEVWHP PDDVAARLRTAGFGAVGAGATAEETR 1224

HSV2 UL30 1133 PGGASKPRKLLV---SELAEDPGYAIARGVPLNTDYYFSHLLGAACVTFKALFGNNAKITESLLKRFIPE TWHP PDDVAARLRAAGFGPAGAGATAEETR 1229

VZV ORF28 1070 RCGEAKRKLIIS----DLAEDPIHVTSHGLS LNIDYYFSHLIGTASVTFKALFGNDTKLTERLLKRFIPE TRVVNVKMLNRLQAAGFVCIHAPCWDNKMN 1165

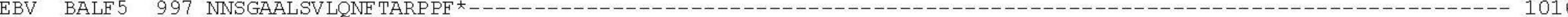

HCMV UL5 1152 PAKKRARKPPSAVCNYEVAEDPSYVREHGVPIHADKYFEQVLKAVTNVLSPVE PGGE TARKDKFLHMVLPRRLHLE PAFLPYSVKAHECC *--------- 1242

HHV6 U38 982 KTDIKKEKLLLYLLPMKVYLDETESAIAEVM ${ }^{\star}---$

HHV7 U38 983 KTGTKKEKFLLSTLPLKVYVDQSFCDLTDVL

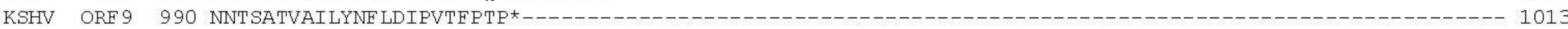

RB69 gP43 890 DYEKKATLFDMFDF*

T4 g043 886 DYEEKASL--DFLF*

Non Visible

HSV1 UL30 1225 RMLHRAFDTLA

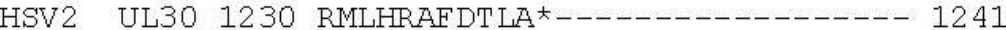

VZV ORF28 1166 TEAEITEEEQSHQIMRRVFCIPKAILHOS* 1195

EBV BLAF 5 - ----------------------

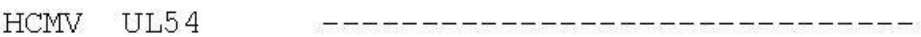

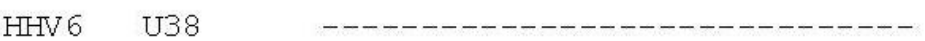

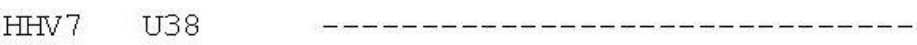

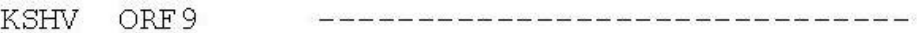

RB69 gp43 -- 3 ---

T4 4 gp43

(C) 2013 by the authors; licensee MDPI, Basel, Switzerland. This article is an open access article distributed under the terms and conditions of the Creative Commons Attribution license (http://creativecommons.org/licenses/by/3.0/). 